\title{
Successful combination of electron spin resonance, luminescence and palaeomagnetic dating methods allows reconstruction of the Pleistocene evolution of the lower Moulouya River (NE Morocco)
}

\author{
Melanie Bartz ${ }^{\mathrm{a}, *}$, Gilles Rixhon ${ }^{\mathrm{b}}$, Mathieu Duval ${ }^{\mathrm{c}}$, Georgina E. King ${ }^{\mathrm{d}}$, Claudia Álvarez Posada ${ }^{\mathrm{e}}$, Josep M. Parés ${ }^{\mathrm{e}}$, \\ Helmut Brückner ${ }^{\mathrm{a}, * *}$ \\ a Institute of Geography, University of Cologne, Albertus-Magnus-Platz, 50923 Cologne, Germany \\ ${ }^{\mathrm{b}}$ Laboratoire Image, Ville, Environnement (LIVE), UMR 7362 - CNRS, University of Strasbourg-ENGEES, 3 rue de l'Argonne, 67000 Strasbourg, France \\ c Australian Research Centre for Human Evolution (ARCHE), Environmental Futures Research Institute (EFRI), Griffith University, 170 Kessels Road, Nathan, QLD 4111, \\ Australia \\ ${ }^{\mathrm{d}}$ Institute of Geological Sciences, University of Bern, Baltzerstr. 1-3, 3012 Bern, Switzerland \\ e Centro Nacional de Investigación sobre la Evolución Humana (CENIEH), Paseo de Atapuerca 3, 09002 Burgos, Spain
}

\section{A R T I C L E I N F O}

\section{Article history:}

Received 10 July 2017

Received in revised form 23 October 2017

Accepted 3 November 2017

Available online $\mathrm{xxx}$

\section{Keywords:}

Calabrian and middle pleistocene

Geochronology

Fluvial sediments

ESR dating

Multiple centres approach

Palaeomagnetic analysis

Palaeoenvironment

\begin{abstract}
A B S T R A C T
Based on a combination of Electron Spin Resonance (ESR) dating of quartz, luminescence dating of $\mathrm{K}$-feldspar and palaeomagnetism, this study presents the first chronostratigraphic framework for the Pleistocene fluvial deposits of the lower Moulouya River (NE Morocco). K-feldspar pIRIR 225 and pIRIR 290 signals of all samples are saturated, suggesting fluvial deposition at least as early as the Middle Pleistocene $(\sim 340-7 \mathrm{R}$. Consequently, further chronological information was obtained with ESR dating of the ancient Pleistoce 2 vial deposits. In aecordanee with the multiple centres approach; equivalent dose values $\theta_{\mathbf{A}}$ the $\mathrm{Al}$ and Ti centres mostly agree within $1 \sigma_{k}$ suggesting a complete bleaching of the signat during fluvial transport. ESR dating results yield Calabrian deposition ages for all river profiles from $\sim 1.1$ to $\sim 1.5 \mathrm{Ma}$, which are remarkably consistent with the palaeomagnetic results: the occurrence of mostly reverse polarity in the deposits indicates $(>0.78 \mathrm{Ma})$. While low incision rates $(0.025 \pm 0.003 \mathrm{~mm} / \mathrm{a})$ related to Calabrian thrusting in the Triffa plain could be inferred, the fluvial record points to an acyclic and discontinuous sedimentation pattern over the last $\sim 1.3 \mathrm{Ma}$. It thereby probably rules out climate as the main driver for fluvial aggradation in the lowermost sedimentary basin. At a regional scale, several indicators point to transient fluvial response resulting from major Quaternary tectonic activity along the Beni Snassen gorge. We suggest that a capture event at the margin of the uplifting Beni Snassen massif occurred between 1.04 and $1.36 \mathrm{Ma}$ at the latest and subsequently led to the creation of the gorge.
\end{abstract}

(C) 2017 .

\section{Introduction}

The investigation of fluvial archives is of significant interest for unravelling palaeoenvironmental changes linked to Quaternary climatic fluctuations (e.g., Macklin et al., 2002; Bridgland and Westaway, 2008) and/or long-term tectonic activity (e.g., Demir et al., 2012; Demoulin et al., 2017). In the western Mediterranean, a sharp contrast exists between the well-studied fluvial systems draining the Iberian Peninsula (e.g., Macklin et al., 2002; Santisteban and Schulte, 2007; Wolf et al., 2014; Benito et al., 2015), also on longer timescales (Schulte et al., 2008; Martins et al., 2010; Soria-Jáuregui et al., 2016; Cunha et al., 2017), and those draining the north-western part of Africa, which remain poorly investigated so far. This is especially true for the Quaternary fluvial landscape evolution resulting

\footnotetext{
* Corresponding author

** Corresponding author.

Email addresses: m.bartz@uni-koeln.de (M. Bartz); h.brueckner@uni-koeln.de (H. Brückner)
}

from interplays between tectonic and climatic drivers. With the exception of studies dealing with the reconstruction of palaeoenvironmental changes together with human-environment interactions on a few local river reaches in North Africa over the last $30 \mathrm{ka}$ (e.g., Barathon et al., 2000; El Amrani et al., 2008; Zielhofer et al., 2008, 2010), chronological data for river archives predating the MIS 2 are almost absent in this region.

Consequently, the Pleistocene palaeoenvironment of North Morocco is as yet poorly investigated. Drained by the Moulouya River, one of the largest river systems in North Africa, the north-eastern part of Morocco is characterised by complex geodynamics due to its location within the convergent zone between the African and Eurasian plates (e.g., Meghraoui et al., 1996). Crustal deformation related to the main W-E striking deformational front between the Rif belt and the Atlas mountains affected the lowermost $\sim 65 \mathrm{~km}$-long reach of the Moulouya during the Pliocene and Quaternary (Barcos et al., 2014; Rixhon et al., 2017a). This resulted in contrasting fluvial environments on each side of a W-E striking thrust zone in this area: thick, stacked terraces in the footwall and a terrace staircase in the hanging- 
wall (Rixhon et al., 2017a). Nevertheless, the timing of fluvial aggradation and terrace formation over the Pleistocene as yet remains very poorly constraint in the Moulouya valley and, overall, in all river systems draining this convergent zone in NE Morocco.

Establishing chronologies for river terrace sequences remains challenging, but represents a key task for understanding fluvial landscape development (Rixhon et al., 2017b). In the northern catchment of the lower Moulouya River it has been shown that the upper dating range of quartz lies at $\sim 70 \mathrm{ka}$ (Bartz et al., 2015). Alternatively, feldspar IRSL dating may serve as valuable tool for dating old Pleistocene deposits (Buylaert et al., 2012), as demonstrated by the studies of Cunha et al. (2008) and Martins et al. (2010) in the fluvial context. While IRSL ages may suffer from anomalous fading, leading to a loss of signal over time (e.g., Wintle, 1973; Huntley and Lamothe, 2001), elevated temperature post-infrared infrared (pIRIR) stimulated luminescence offers feldspar signals which are less or unaffected by anomalous fading (Thomsen et al., 2008; Thiel et al., 2011a). However, even for pIRIR signals, anomalous fading can result in luminescence signals which appear finite, but may reflect an equilibrium level between electron trapping and detrapping via anomalous fading. An athermal detrapping model (cf., Huntley, 2006; Kars et al., 2008) can be used to screen samples for this effect, and the reliability of this model has been tested in a range of studies (e.g., Li and Li, 2008; Kars and Wallinga, 2009; Guralnik et al., 2015). In contrast with luminescence methods, electron spin resonance (ESR) dating of optically bleached quartz grains potentially covers the whole Quaternary (e.g., Voinchet et al., 2010; Duval et al., 2017). In particular, the reliability of the method has been recently improved by the development of the multiple centres (MC) approach (Toyoda et al., 2000): the systematic measurement of both the $\mathrm{Al}$ and the Ti centres in quartz offers the possibility to produce more robust ages (see an overview in Duval et al., 2017). In addition to the use of luminescence and ESR dating techniques, palaeomagnetic analyses have been applied to the same Moulouya deposits in order to independently check our newly established chronological framework. Palaeomagnetism has long proven its usefulness to provide additional chronological constraints to river terrace deposits (e.g., Jacobson et al., 1988; Li et al., 1997; Sancho et al., 2016).

In summary, our study aims to (i) present the first geochronological framework for fluvial deposition in the lower Moulouya valley, based on a combination of ESR dating of quartz using the MC approach, luminescence dating and palaeomagnetic analysis applied together on four different sections along the Moulouya River; (ii) compare the merits of each dating method; (iii) use luminescence dating techniques to study IRSL signals and field saturation, and (iv) provide new insights into the long-term geomorphological evolution of this region of Morocco in comparison with other areas of the Mediterranean.

\section{Study area}

\subsection{Geodynamic background}

The NW-SE convergence between Africa and Iberia in the Straits of Gibraltar from the Miocene to the Quaternary has strongly affected the northern part of Morocco. Crustal deformation in the Western Mediterranean most likely results from the shortening of the Betic-Rif mountain ranges and extension of the Alborán Sea (e.g., Fadil et al., 2006). Indicated by kinematic analyses of fault populations in the Rif and Tell Atlas, shortening directions and rates are characterised by a clockwise block rotation of $15-25^{\circ}$ (from NNE to NNW) and by movements of 1-2.3 mm/a, respectively (Meghraoui et al., 1996;
Meghraoui and Pondrelli, 2012). The Rif mountain range showed NE-SW folding during the Quaternary characterised by left-lateral, strike-slip faults and associated overthrust structures (Meghraoui and Pondrelli, 2012). For instance, horizontal and vertical slip rates of $\sim 0.9$ and $\sim 0.5 \mathrm{~mm} / \mathrm{a}$, respectively, have been determined for the Trougout fault in the northeastern Rif region (Poujol et al., 2014). Trend-topography surface analyses highlighted an E-W trending lithospheric dome in the eastern Rif and in the Beni Snassen massif (Barcos et al., 2014). The latter is affected by N-S shortening resulting in active deformations at its northern margin according to morphometric indicators (Barcos et al., 2014). A disequilibrium state of the Moulouya catchment is reflected by anomalies in its drainage network and the presence of large knickpoints (Barcos et al., 2014; Pastor et al., 2015; Rixhon et al., 2017a). At last, deformation affecting Middle Pleistocene terraces in areas westward (Oued Kert) and eastward (Oujda region) of the Moulouya River was also reported (Ait Brahim et al., 2002).

\subsection{The Moulouya catchment}

\subsubsection{Geological and geomorphological settings}

The Moulouya, with a drainage area of $\sim 74.000 \mathrm{~km}^{2}$ (Fig. 1), represents the largest fluvial system in NE Morocco (Pastor et al., 2015). From its headwaters at the junction of the High and Middle Atlas to the outlet into the Mediterranean Sea, the $\sim 600 \mathrm{~km}$-long, SW-NE oriented main trunk flows across the Neogene Arhbalou, Ksabi-Missour and Guercif basins as well as the Zebra-Triffa basin and Ouled Mansour plateau (Fig. 1; Pastor et al., 2015; Rixhon et al., 2017a). The upper reaches (Arhbalou basin), encompassing the southern to south-eastern foot slopes of the Middle Atlas and the northernmost flanks of the High Atlas, are composed of Palaeozoic rocks affected by the Hercynian orogeny. In the middle reaches (Ksabi-Missour and Guercif basins), the Moulouya drains the western flanks of the Moroccan High Plateaus. The lower reaches (Triffa basin and Ouled Mansour plateau) are mostly filled by Neogene marine sediments (Fig. 2a; Ruellan, 1971; Boughriba et al., 2006). The depression is bordered by the Beni Snassen Mountains to the south and the Kebdana Mountains to the north. Both mainly consist of Mesozoic carbonate rocks, sandstone and slate formations (Ruellan, 1971; Khattach et al., 2004).

\subsubsection{Fluvial archives in the lowermost Moulouya reach}

Our study area encompasses the $\sim 20 \mathrm{~km}$-long river reach draining the northwestern rim of the Triffa basin and the Ouled Mansour plateau (Fig. 2b). Recently, Rixhon et al. (2017a) have highlighted contrasting fluvial environments on both sides of a W-E trending thrust zone. In the northern hanging-wall, a terrace staircase encompasses three Pleistocene terrace levels, i.e., T1, T2 and T3 (Fig. $2 \mathrm{~b}$ and $\mathrm{c}$ ), whose bases lie at relative elevations of $\sim 68, \sim 36$ and $\sim 26 \mathrm{~m}$ above the modern stream bed, respectively. The contact with the Neogene marine bedrock, composed either of partly cemented sands under T1 and T2 or marls under T3, is clearly identifiable at the base of each terrace section (Rixhon et al., 2017a). The general sedimentary sequence of these fluvial terraces is composed of m-thick, massive gravel bodies, strongly cemented due to the induration of the matrix material, overlain by several m-thick fine-grained sediments and all sealed by a several dm-thick, locally dismantled calcrete. Pluri-decimetric boulders, locally occurring in the terrace sections (e.g., DOE profile; Rixhon et al., 2017a), strongly point to high stream power and transport capacities, similar to observations reported in Pleistocene river deposits in SE Spain (Schulte, 2002). Frequent cemented sand lenses, locally exhibiting cross-bedding, are embedded in the gravel bodies. Three distinct levels are also recognised in the 


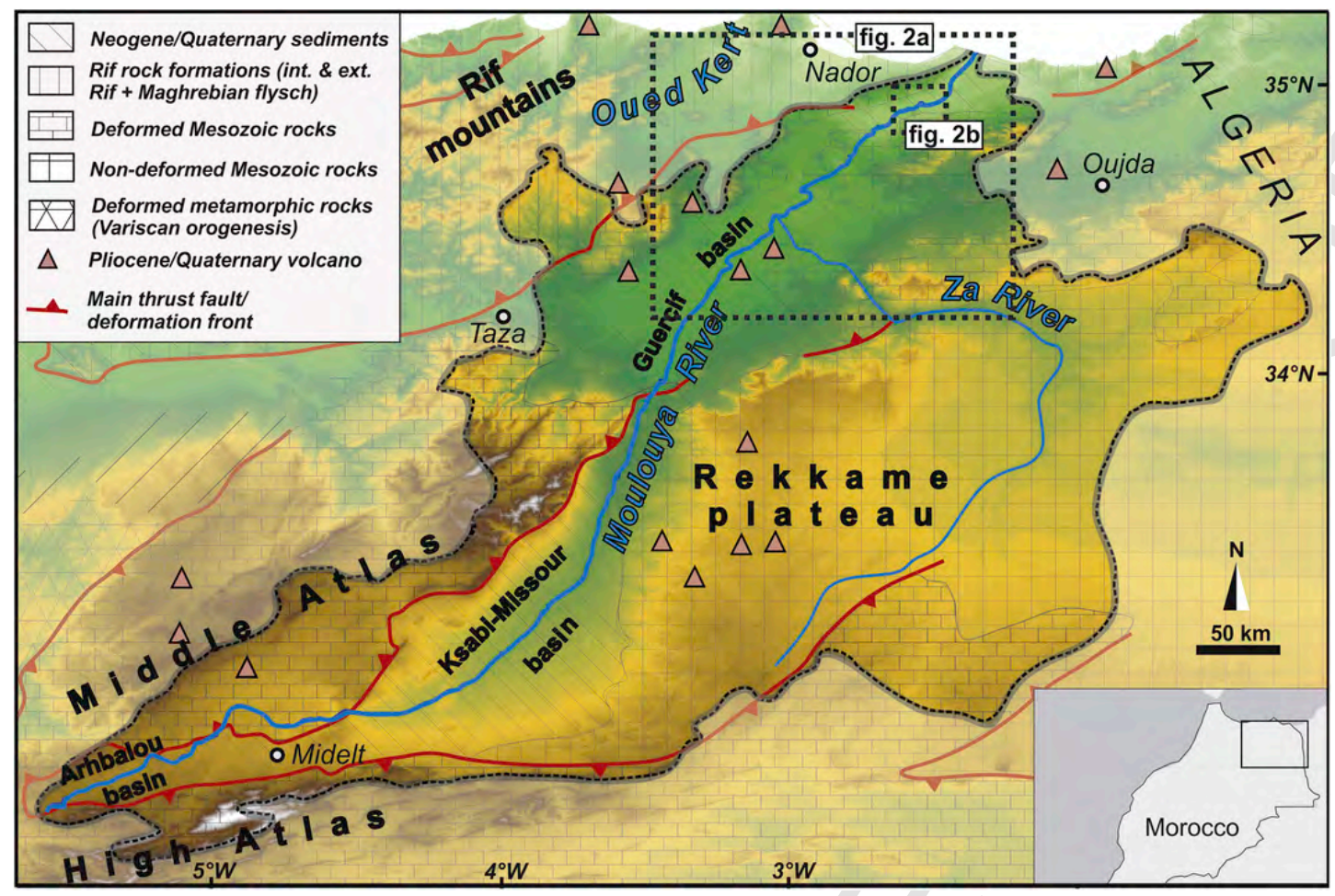

Fig. 1. Relief map of the Moulouya catchment (delimited by dashed black lines) including the main geological structures (according to Barcos et al., 2014).

fine-grained Holocene deposits with elevations above the current stream of $\sim 14, \sim 6$ and $\sim 3 \mathrm{~m}$ (Pissart and Boumeaza, 2010; Rixhon et al., 2017a). In the southern footwall, up to $37 \mathrm{~m}$-high stacked terraces characterised by two fining-upward sequences bear witness to long-lasting fluvial aggradation (Rixhon et al., 2017a). No Neogene marine sediment can be observed at the base of the fluvial sections. The latter are formed by several m-thick cemented river gravels, capped by fine-grained sediments exhibiting several dm-thick calcretes at the top (Rixhon et al., 2017a). Holocene overbank fines, as attested by archaeological findings (Linstädter et al., 2012), locally overlie the cemented river gravels. A strath terrace with sculpted fluvial features, located ca. 3-4 m above the present-day channel, is observed $\sim 2 \mathrm{~km}$ upstream of the fault zone on the western valley side (Fig. 2b and c; Rixhon et al., 2017a).

\section{Field sampling and methods}

\subsection{Sampling sites and strategy}

Our fieldwork focused on four different fluvial sedimentary sequences, located either in the footwall of the fault zone (sections BOU, TOLL, MRB) or in the hanging wall (DOE section in terrace T3; see Rixhon et al., 2017a) (Fig. 2b). Sampling strategy at these sections for geochronological purpose mostly depended on the degree of cementation of the deposits, sometimes preventing thus any kind of sampling, and the local homogeneity of the sediment to facilitate an accurate dose rate reconstruction.

BOU is a $\sim 22 \mathrm{~m}$-high section (Fig. 3a and b), located on the northern bank of the Moulouya River, $\sim 9 \mathrm{~km}$ upstream of the fault zone $\left(34^{\circ} 56^{\prime} 57.4^{\prime \prime} \mathrm{N} ; 2^{\circ} 32^{\prime} 03.6^{\prime \prime} \mathrm{W}\right.$; $50 \mathrm{~m}$ a.s.l.; above sea level). At our sampling location, up to $15 \mathrm{~m}$-thick Holocene overbank fines (Fig. 3a) hide the lower part of the section (Zielhofer et al., 2008, 2010), but coarse-grained deposits in the basal part are observable in the direct vicinity of the profile. Along the investigated uppermost $\sim 7 \mathrm{~m}$ of the profile, we identify one unit: clast-supported layers show an alternation of finer and coarser gravel layers intercalated by three large sand lenses at 5.6-4.5, 1.9-1.4 and 0.9-0.2 m b.s. (below surface). The uppermost decimetres are characterised by an upward increasing calcrete development.

TOLL is a $\sim 25 \mathrm{~m}$-high section (Fig. $3 \mathrm{c}$ and d), located on the southern bank of the Moulouya River, $\sim 8 \mathrm{~km}$ upstream of the fault zone $\left(34^{\circ} 56^{\prime} 27.2^{\prime \prime} \mathrm{N} ; 2^{\circ} 31^{\prime} 47.5^{\prime \prime} \mathrm{W} ; 50 \mathrm{~m}\right.$ a.s.l.). The lower part of unit 1 (25-22 $\mathrm{m}$ b.s.) is characterised by an alternation of matrix-(sand) and clast-(cemented gravels) supported layers. The overlying part of unit 1 (22-20 m b.s.) is characterised by a sharp boundary with a sediment change to homogeneous fine sand showing a fining-upward sequence. Tafoni-like weathering is observed in the upper part of the sand lense. Unit 2 (20-0 m b.s.) is dominated by mostly-cemented coarse-grained sediments. A transition to calcrete is observed in the uppermost metre.

$\mathrm{MRB}$ is a $\sim 34 \mathrm{~m}$-high section (Fig. 3e-g), located on the southern bank of the Moulouya River, $\sim 6 \mathrm{~km}$ upstream of the fault zone $\left(34^{\circ} 56^{\prime} 24.4^{\prime \prime} \mathrm{N} ; \quad 2^{\circ} 30^{\prime} 40.2^{\prime \prime} \mathrm{W} ; 51 \mathrm{~m}\right.$ a.s.1.). The poorly sorted clast-supported unit 1 (34-25 m b.s.) encompasses rounded to subangular gravel up to $35 \mathrm{~cm}$ in size, where two fine laminated $\sim 1 \mathrm{~m}$-thick sand lenses are intercalated. The upper part (25-22 $\mathrm{m} \mathrm{b.s.)}$ of unit 1 is composed of tafoni-like sand deposits. Unit 2 is formed by carbonate-cemented clasts (22-13 m b.s.) and overlying middle to coarse sandy deposits (13-10 m b.s.). The top of unit $2(11-10 \mathrm{~m}$ b.s.) is formed by a channel-like gravel layer. The upper unit 3 (10-0 m b.s.) consists of silt and clay-rich deposits, whilst the upper part is composed of a ca. $1 \mathrm{~m}$-thick calcrete layer.

DOE is a $\sim 23 \mathrm{~m}$-high section (Fig. $3 \mathrm{~h}$ and i), located on the eastern bank of the Moulouya River, $\sim 2 \mathrm{~km}$ downstream of the fault zone $\left(34^{\circ} 59^{\prime} 59.2^{\prime \prime} \mathrm{N} ; 2^{\circ} 26^{\prime} 27.3^{\prime \prime} \mathrm{W} ; 50 \mathrm{~m}\right.$ a.s.1.). A detailed stratigraphic description is provided in Rixhon et al. (2017a). 


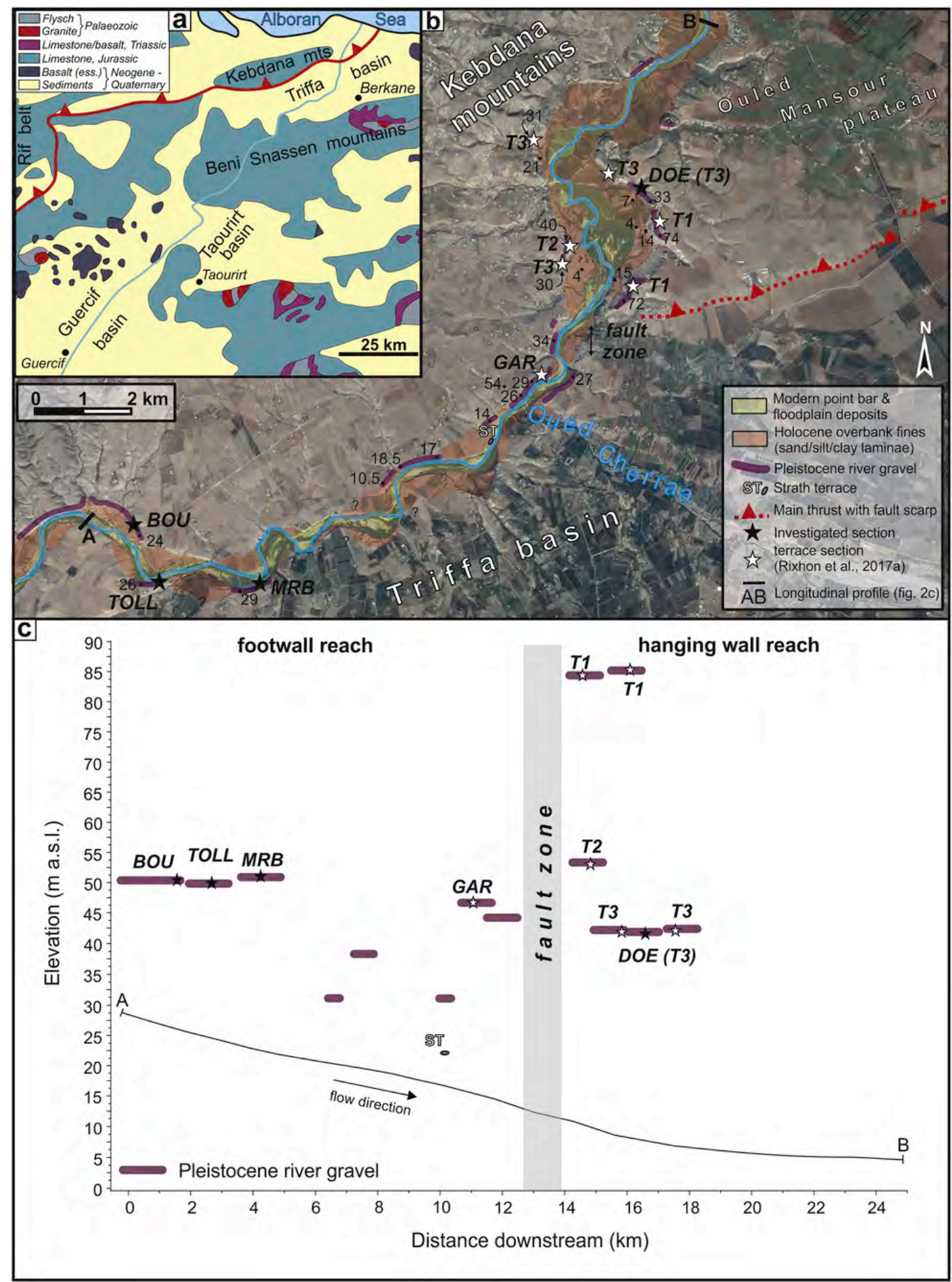

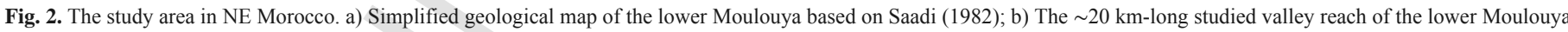

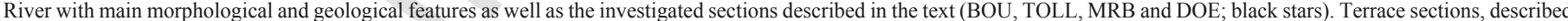

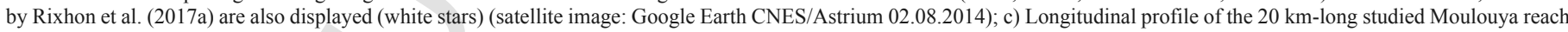

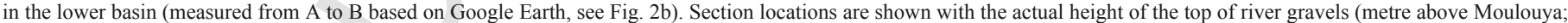
$\mathrm{m}$ a.M.). Both river sections, investigated in this study (black stars) and reported by Rixhon et al. (2017a) (white stars), are presented.

For luminescence and ESR dating, we hammered steel tubes ( $25 \mathrm{~cm}$ long cylinder with a diameter of $5 \mathrm{~cm}$ ) in the freshly cleaned vertical sections of the investigated profiles. The tubes were directly sealed from sunlight with opaque tape and black bags. Whenever possible, sediment samples for dating analyses were collected within homogeneous layers in order to minimise the uncertainty on the ex- 


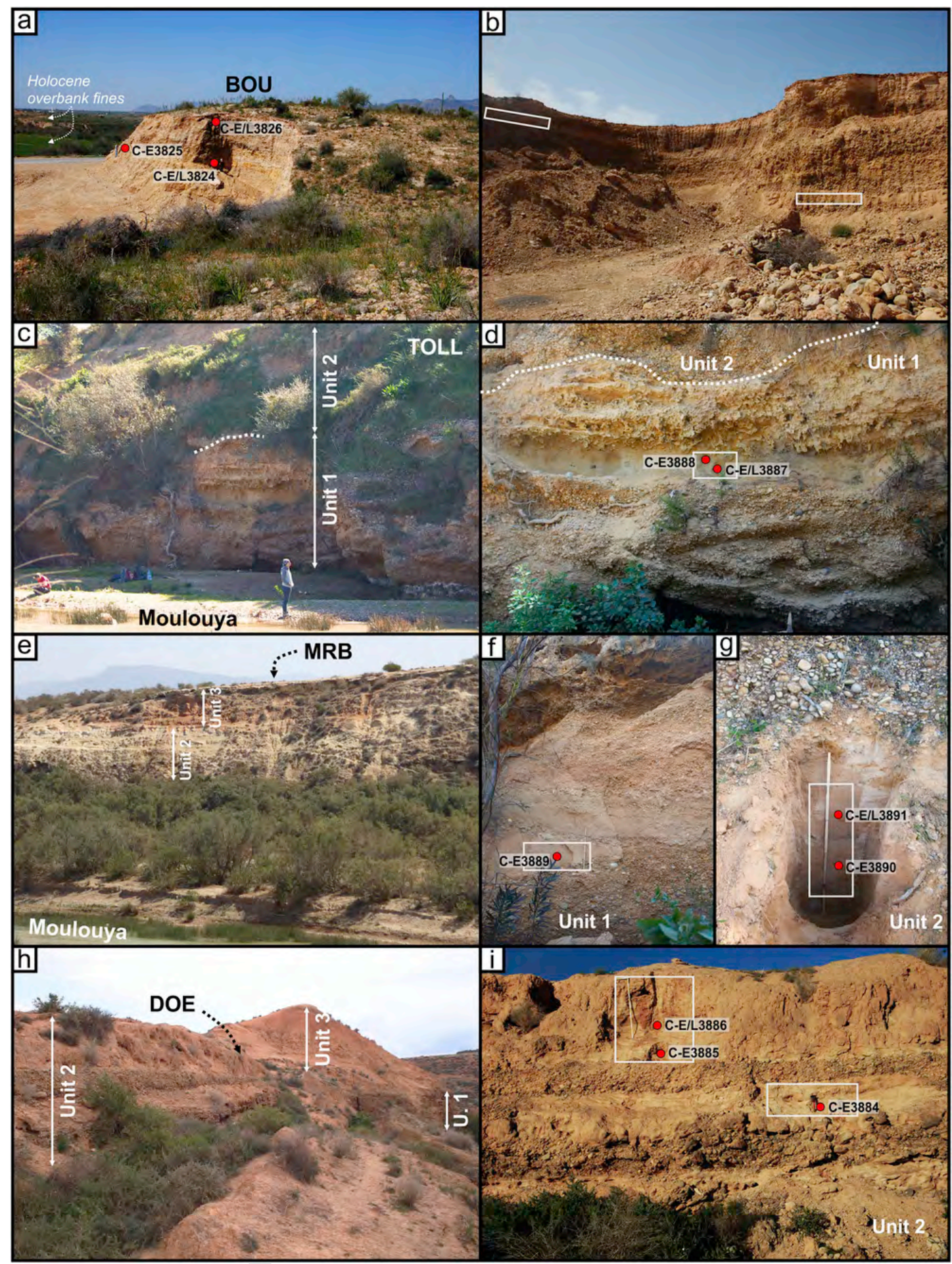

Fig. 3. Field views of the four investigated fluvial profiles. ESR/luminescence (C-E/L; red circles) and palaeomagnetic (white rectangles) sample sites are shown within specific units (see text for details) of each section. Photographs are taken by G. Rixhon and M. Bartz. a-b) BOU section (photo a: 2014; b: 2016), person for scale; c-d) TOLL section (photos: 2015), person and hammer for scale; e-g) MRB section (photos: 2015), tape measure for scale; h-i) DOE section (photos: 2015; see also Rixhon et al., 2017a), tape measure and hammer for scale. (For interpretation of the references to colour in this figure legend, the reader is referred to the web version of this article.)

ternal dose rate due to the absence of in situ gamma measurements. The surrounding material, in a radius of $30 \mathrm{~cm}$, was additionally collected for high-resolution $\gamma$-spectrometry (HRGS), ICP-MS analyses and water content evaluations. For palaeomagnetic analysis, we sampled the same sections as for luminescence/ESR dating. A ceramic knife was used to extract hand blocks and a solution of sodium silicate was applied in order to preserve the integrity of the samples. All palaeomagnetic samples were oriented in the field using standard compass and clinometer. 
Several samples were collected at each locality (Fig. 3): At the BOU section, three ESR/luminescence samples (C-E/L3824-3826) were extracted at depths of $\sim 5.3, \sim 1.5$ and $\sim 0.5 \mathrm{~m}$ b.s. In addition, twelve palaeomagnetic samples were collected at depths of 7.1-7.3 (B1.1-1.3), 6.1-6.2 (B2.1-2.3), 2.3-2.6 (B3.1-3.3) and 6.5-6.8 m b.s. (B4.1-4.3). At the TOLL section, two ESR/luminescence samples (C-E/L3887-3888) were collected at depths of $\sim 21.4$ and $\sim 21.6 \mathrm{~m}$ b.s. Three palaeomagnetic samples were extracted from the same sand lense horizontally at depth of $21.5 \mathrm{~m}$ b.s. (T1.1-1.3). At the MRB section, three ESR/luminescence samples (C-E/L3889-3891) were collected at depths of $\sim 30.0, \sim 13.8$ and $\sim 13.4 \mathrm{~m}$ b.s. For palaeomagnetic analysis, six samples were collected at depths of 13.4 (M1.1-1.3) and 29.5-29.9 m b.s. (M2.1-2.3). At the DOE section, three ESR/luminescence samples (C-E/L3884-3886) were extracted at depths of $\sim 3.2, \sim 1.9$, and $\sim 1.2 \mathrm{~m}$ b.s. In addition, palaeomagnetic samples were collected at 1.95-2.15 (D1.1-1.3), 2.65-2.85 (D2.1-2.3), 3.65-3.85 (D3.1-3.3) and 1.55-1.65 m b.s. (D4.1-4.2), respectively.

\subsection{Sample preparation}

Sample preparation for luminescence and ESR dating was undertaken under subdued red light conditions at the Cologne Luminescence Laboratory (CLL), University of Cologne. We separated the sample material of each tube in two parts to prepare luminescence (sample names C-L) and ESR (sample names C-E) sample material. After wet sieving, coarse-grained $(100-200 \mu \mathrm{m})$ sediments were treated with $\mathrm{H}_{2} \mathrm{O}_{2}(10 \%), \mathrm{HCl}(10 \%)$ and sodium oxalate to remove carbonates, organic material and clay remains. Density separation with sodium polytungstate was performed to isolate quartz $\left(\rho_{1}=2.62-2.68 \mathrm{~g} \mathrm{~cm}^{-3}\right)$ and K-feldspars $\left(\rho_{2}=<2.58 \mathrm{~g} \mathrm{~cm}^{-3}\right)$. Magnetic minerals were removed by using a strong neodymium magnet. The resulting quartz minerals were etched with HF (40\%) for 40 min plus a final $\mathrm{HCl}(10 \%)$ wash. For luminescence dating, K-feldspars were additionally sieved to grain sizes of $100-150 \mu \mathrm{m}$ and mounted on stainless steel discs. K-feldspar samples were not etched (Duller, 1992). Each quartz ESR sample (100-200 $\mu \mathrm{m})$ was divided into 12 aliquots. Whilst 1 aliquot was kept as a natural reference, 10 aliquots were irradiated with a calibrated Gammacell-1000 Cs-137 gamma source $($ dose rate $=6.8 \mathrm{~Gy} / \mathrm{min})$ to $100.0,200.0,394.6$, 796.1, 1598.9, 3197.9, 6001.1, 10003.1, 15002.8 and 25018.1 Gy. Additionally, 1 aliquot was optically bleached in a solar simulator (Hönle SOL2) for about $1500 \mathrm{~h}$. For palaeomagnetic analyses the 13 hand block samples were separated into 118 cubic specimens of $\sim 8 \mathrm{~cm}^{3}$ each.

\subsection{ESR measurements}

Low temperature $(\sim 90.0 \pm 0.1 \mathrm{~K})$ ESR measurements were carried out at the Geochronology Facilities in the Centro Nacional de Investigación sobre la Evolución Humana (CENIEH, Burgos) with an EMXmicro 6/1 Bruker X-band ESR spectrometer coupled to a standard rectangular ER4102ST cavity and using a ER4141VT Digital Temperature control system based on liquid nitrogen cooling. Further details about the experimental setup and its stability may be found in Duval and Guilarte Moreno (2012).

Eleven samples were ESR dated with the MC approach by means of the multiple-aliquot additive-dose method (MAAD) following the same analytical procedure as described in Duval et al. (2015). The Al ESR intensity was measured between the top of the first peak $(\mathrm{g}=2.018)$ and the bottom of the 16th peak $(\mathrm{g}=1.993)$ (Toyoda and Falguères, 2003). ESR intensities of the Ti centre were extracted from four different options, namely A, C (pure Ti-H), D and E (pure Ti-Li) as described in Duval and Guilarte (2015). Full details are provided in supplementary material (Appendix A). ESR intensities of $\mathrm{Al}$ and Ti centres of each aliquot were then corrected by the corresponding number of scans, aliquot mass and a temperature correction factor (Duval and Guilarte Moreno, 2012). Fitting procedure and $\mathrm{D}_{\mathrm{e}}$ calculation were performed with Microcal OriginPro 8.5 software. Al ESR intensities were fitted with an exponential + linear (EXPLIN) function following Duval (2012) with data points weighted by the inverse of the squared ESR intensity $\left(1 / \mathrm{I}^{2}\right)$. Ti ESR intensities were fitted with the Ti-2 function as in Duval and Guilarte (2015), with either equal weights or data points weighted by the inverse of the squared experimental errors $\left(1 / \mathrm{s}^{2}\right)$. For comparison, the Ti ESR intensities were additionally fitted with the single saturation exponential (SSE) function $\left(1 / \mathrm{I}^{2}\right)$ until the maximum ESR intensity $\left(\mathrm{I}_{\max }\right)$. Fitting equations and full details about the fitting procedure and $\mathrm{D}_{\mathrm{e}}$ calculation can be found in supplementary material (Appendix A).

\subsection{Luminescence measurements}

All luminescence measurements were carried out at the CLL on automated Risø TL/OSL-DA-20 readers equipped with ${ }^{90} \mathrm{Sr} /{ }^{90} \mathrm{Y}$ beta sources for irradiation and delivering dose rates of $\sim 0.08 \mathrm{~Gy} / \mathrm{s}$. IR stimulation $(880 \pm 80 \mathrm{~nm})$ and signal detection through an interference filter $(410 \mathrm{~nm})$ was used for measuring the coarse-grained $\mathrm{K}$-feldspar samples. An elevated temperature pIRIR single-aliquot regenerative-dose (SAR) protocol was applied using a second IR stimulation temperature of either $225^{\circ} \mathrm{C}$ (pIRIR 225 ; Buylaert et al., 2009) or $290{ }^{\circ} \mathrm{C}$ (pIRIR 290 ; Thiel et al., 2011a) after a preheat of 260 or $320^{\circ} \mathrm{C}$ (both held for $60 \mathrm{~s}$ ), respectively. At the end of each SAR cycle an IR stimulation at $290\left(\mathrm{pIRIR}_{225}\right)$ or $325^{\circ} \mathrm{C}\left(\mathrm{pIRIR}_{290}\right)$ was used for $100 \mathrm{~s}$ to reduce recuperation. The response to a test dose $(\sim 30 \%$ of the expected natural equivalent dose, $\mathrm{D}_{\mathrm{e}}$ ) was measured in the same way for both pIRIR protocols. After measurement of the natural $\mathrm{pIRIR}_{225}$ or pIRIR 290 signal, athermal signal loss was estimated using fading tests following Auclair et al. (2003) for both the prior IR and pIRIR measurements of one sample per sediment profile (samples C-L3824, C-L3826, C-L3886, C-L3887 and C-L3891). Three aliquots (1 mm diameter) per sample were measured in order to average sample specific g-values, which were normalised to a measurement delay time of 2 days after irradiation ( $\mathrm{g}_{2 \text { days }}$; Huntley and Lamothe, 2001). Regenerative doses of $350 \mathrm{~Gy}$ and test doses of $125 \mathrm{~Gy}$ were used in the fading experiments. A prompt measurement was repeated after the longest measured delay in order to confirm that sensitivity changes had been adequately corrected for. The model of athermal detrapping first proposed by Huntley (2006) and modified by Kars et al. (2008) was used to estimate sample specific field saturation $(\mathrm{n} / \mathrm{N})_{\mathrm{ss}}$ (Huntley and Lian, 2006), in which the natural IRSL intensity is governed only by the competing rates of signal accumulation due to environmental radiation and signal loss by anomalous fading (Kars et al., 2008). We used a $15 \%$ acceptance threshold of the environmental steady state level (Guralnik et al., 2015; King et al., 2016) in order to account for the uncertainty of interpolating a $\mathrm{D}_{\mathrm{e}}$ value on a dose response curve close to saturation (Wintle and Murray, 2006).

\subsection{Dose rate evaluation and age calculation}

Radioelement activities (U, Th and K) were obtained by HRGS analysis using a high-purity germanium detector in the CLL. In addition, ICP-MS measurement of dry raw material was done by Genalysis Laboratory Services. The software DRAC v1.2 (Durcan et al., 
2015) was used for dose rate and age calculation using the conversion factors of Guérin et al. (2011) and alpha and beta attenuation factors of Bell (1980) and Guérin et al. (2012) (specifically chosen for either quartz or feldspar), respectively. The depth removed by HF etching was assumed to be $20 \pm 10 \mu \mathrm{m}$. Water contents (mass of water relative to the dry sample) were measured in the laboratory. The contribution of the cosmic dose rate was assessed following the approach of Prescott and Hutton (1994) based on the altitude, latitude and longitude of the section, as well as the thickness and density of overlying sediments. The latter was assumed to be $1.90 \pm 0.05 \mathrm{~g} / \mathrm{cm}^{3}$. For ESR dating of quartz, dose rate evaluation was done with an assumed $\alpha$-efficiency k-value of $0.2 \pm 0.1$ (Yokoyama et al., 1985) and an assumed internal dose rate of $0.05 \pm 0.03 \mathrm{~Gy} / \mathrm{ka}$ (Vandenberghe et al., 2008). For coarse-grained feldspar, an $\alpha$-efficiency of $0.11 \pm 0.03$ (Balescu and Lamothe, 1993) and an internal potassium content of $12.5 \pm 0.5 \%$ (Huntley and Baril, 1997) were assumed.

\subsection{Palaeomagnetic analysis procedures}

Palaeomagnetic analyses were carried out at the Geochronology Facilities in the CENIEH. The natural remanent magnetisation (NRM) and progressive demagnetisation of each specimen was measured by using a Superconducting Rock Magnetometer (SRM) model 755-4K ( $2 \mathrm{G}$ Enterprises). A total of 52 specimens were analysed by thermal demagnetisation (TH) using an oven model TD-48SC (ASC Scientific) with progressively increasing steps between 50 and $650{ }^{\circ} \mathrm{C}$, whilst 49 specimens were demagnetised by the alternating field method (AF) using the 3-axis degausser system built in the SRM, reaching a maximum AF field of $0.1 \mathrm{~T}$. Finally, after visual inspection of the orthogonal demagnetisation diagrams (Zijderveld, 1967), the characteristic remanent magnetisation (ChRM) direction was computed for each demagnetised specimen, which is the highest stability component of the NRM by using the Virtual Palaeomagnetic Directions (VPD) (Ramón and Pueyo, 2012). The corresponding virtual geomagnetic pole (VGP) position (latitude and longitude of the VGP) was computed for each ChRM direction, which were used to determine the local magnetic polarity at site level (using the software package Pmag by Tauxe, 1998).

\subsection{Quantifying fluvial incision}

DGPS (Topcon HiPer Pro) and laser distance meter (TruPulse 200 Rangefinger) were used in order to estimate the relative elevations of the fluvial terrace surfaces and the modern floodplain (cf., Rixhon et al., 2017a). Fluvial incision rates were then estimated by using the age and the height of the terrace's tread with regard to the current Moulouya floodplain (e.g., Burbank and Anderson, 2012).

\section{Geochronological framework}

\subsection{Palaeomagnetic analyses}

Palaeomagnetic results show that the studied lithologies have medium NRM intensities (Fig. 4a), with values ranging between $2.05 \times 10^{-4} \mathrm{~A} / \mathrm{m}$ to $8.11 \times 10^{-2} \mathrm{~A} / \mathrm{m}$. For the BOU section, NRM intensities range between $2.71 \times 10^{-3} \mathrm{~A} / \mathrm{m}$ to $8.11 \times 10^{-2} \mathrm{~A} / \mathrm{m} .16$ of 32 specimens have been demagnetised by thermal demagnetisation (TH), whilst the other 16 specimens have been processed by the alternating field method (AF). The results show a dominance of southeast and negative directions. A total of 10 specimens have been processed from the TOLL section, with a range of NRM intensities between $8.66 \times 10^{-3} \mathrm{~A} / \mathrm{m}$ and $1.40 \times 10^{-2} \mathrm{~A} / \mathrm{m}$. 5 of those subsamples have been demagnetised by $\mathrm{TH}$ and the other 5 by AF. In contrast to the other sections, TOLL display to the north to northeast and downwards directions. Many specimens from the MRB section were either unstable upon demagnetisation or too weak after the initial demagnetisation steps. As a consequence, only sample M2 (18 specimens) has reproducible and interpretable results. NRM intensities range between $1.75 \times 10^{-3} \mathrm{~A} / \mathrm{m}$ and $6.52 \times 10^{-3} \mathrm{~A} / \mathrm{m}$. Whilst 7 of those subsamples have been analysed by $\mathrm{TH}$ demagnetisation, AF demagnetisation was used to analyse the other 11 specimens. The results show a south-west direction and upwards inclination. NRM intensities from 39 specimens of the DOE section range between $2.05 \times 10^{-4} \mathrm{~A} / \mathrm{m}$ and $1.09 \times 10^{-3} \mathrm{~A} / \mathrm{m} .23$ specimens have been demagnetised by $\mathrm{TH}$ and the remaining by AF. The ChRM directions in this site, similar to the BOU section, are southeast, and upwards.

Both thermal and alternating field demagnetisation procedures reveal that most samples have a secondary, viscous overprint, followed by a high temperature (or coercivity) component of magnetisation.

VGP pole positions (Fig. $4 \mathrm{~b}$ and Table 1) indicate reversed polarity for sections BOU, DOE and MRB, whilst section TOLL reveals normal polarity. The presence of normal polarity in a few specimens from the BOU section can be interpreted as overprinting of the present geomagnetic field (Table 1). In first instance, the reversed polarities observed in several sections provide a first chronological constraint for the deposits as they clearly indicate a pre-Brunhes age $(>0.78 \mathrm{Ma}$; Gradstein et al., 2012).

\subsection{ESR dating of quartz}

\subsubsection{Al centre}

The Al centre (Table 2) of all samples shows ESR intensities with satisfactory repeatability which does not exceed $6 \%$. Most of the samples $(7 / 11)$ present a good $\mathrm{D}_{\mathrm{e}}$ repeatability $(<10 \%)$, while three of them have a variability between 10 and $15 \%$. Only one sample (C-E3825) shows poor repeatability of $\sim 23 \%$. Consequently, final $D_{e}$ values were calculated by considering the average of nine ESR intensities. ESR intensities of the bleached aliquots are within relatively narrow range, between 47 and 57\%, suggesting thus similar bleaching conditions for all the samples.

The DRCs of the Al centre (Fig. 5a; supplementary material Appendix B Fig. B1) of the Moulouya samples does not reach saturation at high dose points up to $25 \mathrm{kGy}$, which is consistent with previous observations (e.g., Lin et al., 2006; Duval, 2012). The EXPLIN function shows excellent goodness-of-fit with adjusted $r^{2}$ values $>0.99$ for the most of our samples (9/11). The only exceptions are samples C-E3825 and C-E3886 resulting both in $\mathrm{r}^{2}$ values of $\sim 0.98$, which indicate moderate goodness-of-fit, yielding then the highest relative $D_{e}$ uncertainties of 21 and $19 \%$, respectively. In contrast, all of the other samples have uncertainties $<14 \%$. Overall, the good measurement and $\mathrm{D}_{\mathrm{e}}$ reproducibility, combined with high goodness-of-fit, indicate the reliability of the fitting results obtained for the $\mathrm{Al}$ centre. Finally, $\mathrm{D}_{\mathrm{e}}$ values (Table 3) range between $1537 \pm 144$ and $1858 \pm 261 \mathrm{~Gy}$ for section DOE, $1147 \pm 144$ and $1747 \pm 244 \mathrm{~Gy}$ for section MRB, $1826 \pm 170$ and $2008 \pm 148$ Gy for section TOLL as well as $1197 \pm 131$ and $1437 \pm 302$ Gy for section BOU.

\subsubsection{Ti centres}

The signal of Ti centres measured in the Moulouya samples (Fig. 5b, see also supplementary material Appendix B Figs. B2-5) exhibit non-monotonic dose-response behaviour: whilst the Ti options A and $\mathrm{D}$ reach a maximum ESR intensity, roughly at $\sim 7 \mathrm{kGy}$ (Fig. 5b), the Ti-H centre saturates at $\sim 3 \mathrm{kGy}$ (Fig. B5). This behaviour is consistent with previous observations by Duval and Guilarte (2015) and 
a
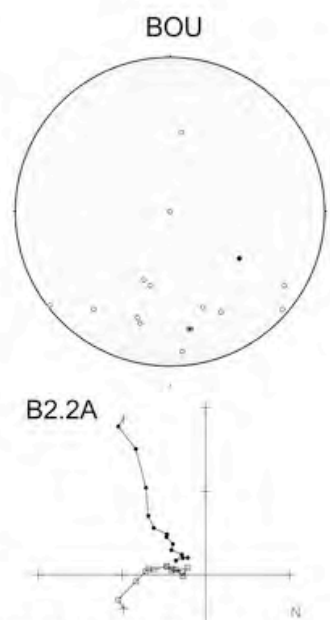

$\mathrm{NRM}=2.15 \mathrm{E}-02 \mathrm{~A} / \mathrm{m}$

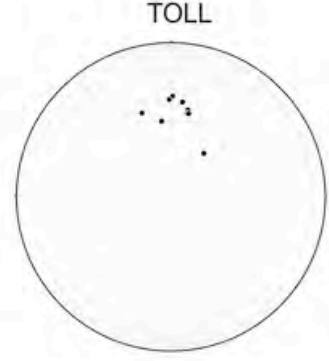

$\mathrm{T} 1 \mathrm{C}$

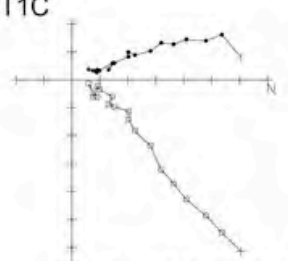

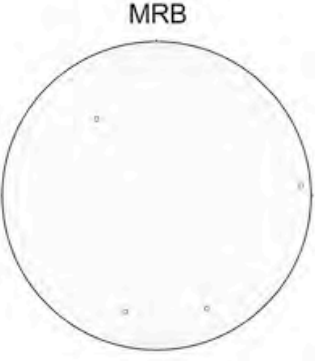

M2.1D

$\mathrm{NRM}=4.19 \mathrm{E}-03 \mathrm{~A} / \mathrm{m}$

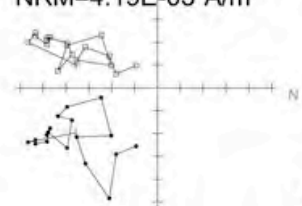

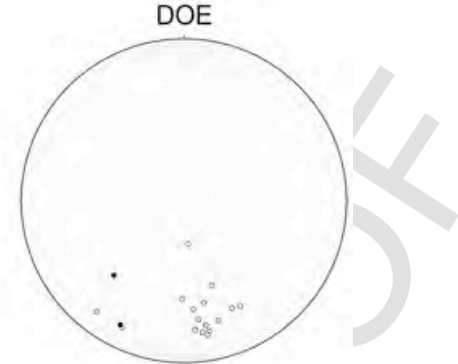

D3.3D

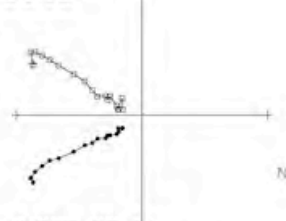

$\mathrm{NRM}=8.66 \mathrm{E}-03 \mathrm{~A} / \mathrm{m}$

$\mathrm{NRM}=1.92 \mathrm{E}-02 \mathrm{~A} / \mathrm{m}$

b

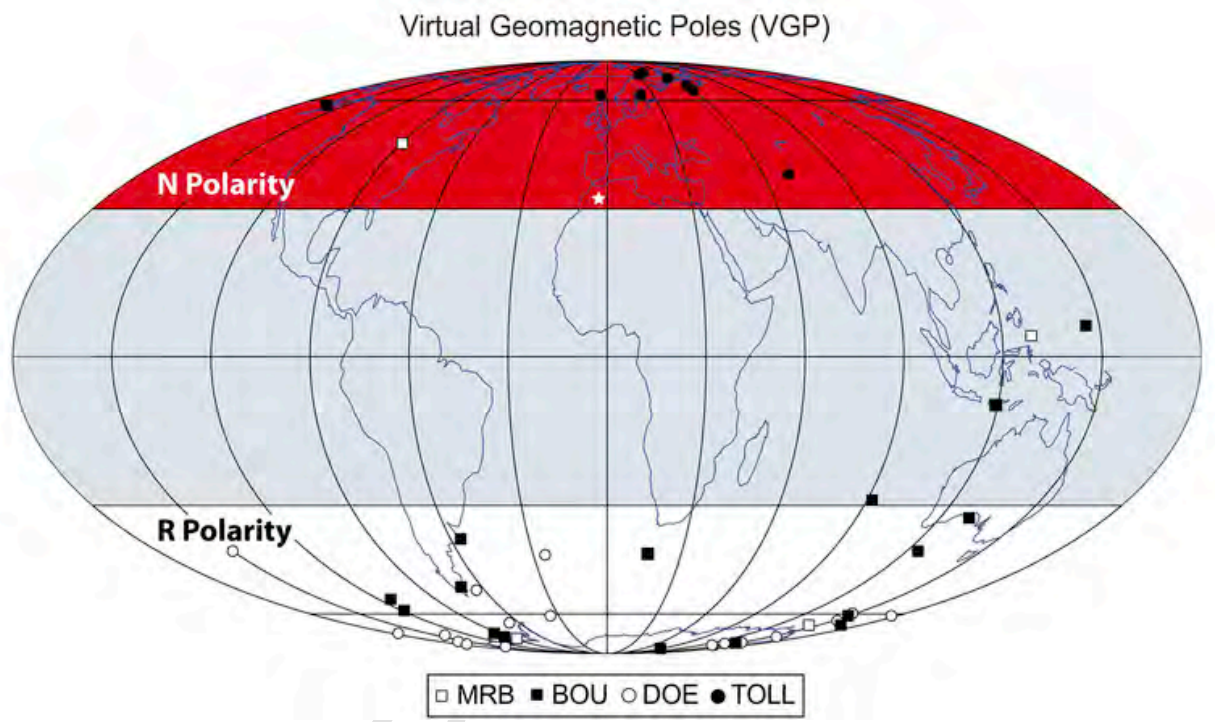

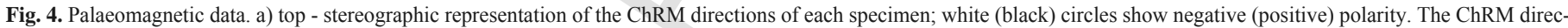

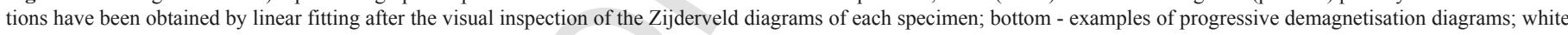

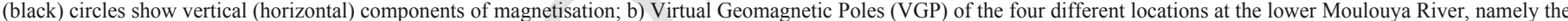

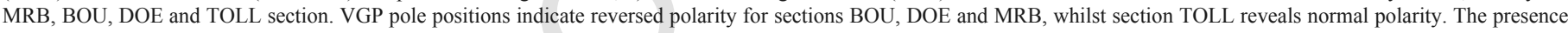
of normal polarity in a few specimens from the BOU section can be interpreted as overprinting by the present day magnetic field.

Woda and Wagner (2007). As expected, Ti centres show complete resetting of the ESR signal after $1500 \mathrm{~h}$ of artificially bleaching (cf., Duval et al., 2017).

Duval et al. (2015) recently showed that among all the options studied for the Ti centres, option $\mathrm{D}$ provides the most reliable results for Calabrian fluvial deposits. Consequently, only those results will be discussed hereafter, although a detailed analysis and comparison of the results derived from options $\mathrm{A}, \mathrm{C}$ (Ti-H centre) and D may be found in supplementary information Appendix B.

Ti option D (Fig. 5b) shows overall satisfactory ESR intensity reproducibility of 3.3 and $6.8 \%$, resulting in good $\mathrm{D}_{\mathrm{e}}$ reproducibility of the three individual measurements with relative variations $<15 \%$ (Table 2), except for samples C-E3887 and C-E3890. The three fitting options tested provide $\mathrm{D}_{\mathrm{e}}$ values that are consistent at $1 \sigma$. As ex- pected the Ti-2 function with equal weights (EW) yield somewhat slightly higher $\mathrm{D}_{\mathrm{e}}$ values in comparison with the Ti-2 function and data weighting by $1 / \mathrm{s}^{2}$. However, the latter is in closer agreement with the SSE function $\left(1 / \mathrm{I}^{2}\right)$, with a mean deviation of $6 \%$. These data show that the fitting function and the data weighting options do not significantly influence the final $\mathrm{D}_{\mathrm{e}}$ results, demonstrating their robustness.

The goodness-of-fit is excellent overall with adjusted $r^{2}$ values systematically $>0.99$ with the Ti-2 function $\left(1 / \mathrm{s}^{2}\right)$, while two samples (C-E3884 and C-E3886) have a slightly lower adjusted $r^{2}$ value of $\sim 0.98$ with the SSE function $\left(1 / \mathrm{I}^{2}\right)$. These data show the good reliability of the fitting results obtained.

Consequently, given the good robustness and reliability of the ESR data collected for the Ti centre option $\mathrm{D}$, final $\mathrm{D}_{\mathrm{e}}$ values were 
Table 1

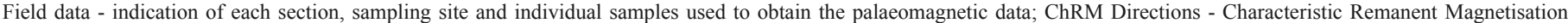

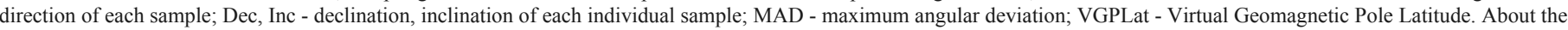
Site Mean distribution: N - number of data points; Dec, Inc - mean declination, inclination of the sampling site; K - precision parameter.

\begin{tabular}{|c|c|c|c|c|c|c|c|c|c|c|c|}
\hline \multicolumn{3}{|c|}{ Field Data } & \multicolumn{3}{|c|}{ ChRM directions } & \multirow[t]{2}{*}{ VGPLat of each individual sample } & \multicolumn{4}{|c|}{ Site Mean Distribution } & \multirow[t]{2}{*}{ VGPLat of each site } \\
\hline Section & Sampling Site & Individual Sample & Dec & Inc & MAD & & $\mathrm{N}$ & Dec & Inc & $K$ & \\
\hline \multirow[t]{16}{*}{$\mathrm{BOU}$} & \multirow[t]{4}{*}{$\mathrm{B} 1$} & $\mathrm{~B} 1.2 \mathrm{~A}$ & 218 & -21 & 14,2 & -51 & \multirow[t]{4}{*}{4} & \multirow[t]{4}{*}{122,8} & \multirow[t]{4}{*}{$-58,1$} & \multirow[t]{4}{*}{1,7} & \multirow[t]{10}{*}{-27} \\
\hline & & $\mathrm{B} 1.3 \mathrm{~A}$ & 83 & -45 & 9,3 & -9 & & & & & \\
\hline & & $\mathrm{B} 1.3 \mathrm{C}$ & 8 & -47 & 9,2 & 58 & & & & & \\
\hline & & $\mathrm{B} 1.3 \mathrm{D}$ & 131 & -4 & 12,7 & -41 & & & & & \\
\hline & \multirow[t]{6}{*}{ B2 } & $\mathrm{B} 2.1 \mathrm{~A}$ & 175 & -10 & 23,9 & -84 & \multirow[t]{6}{*}{6} & \multirow[t]{6}{*}{186,5} & \multirow[t]{6}{*}{$-16,9$} & \multirow[t]{6}{*}{5,2} & \\
\hline & & $\mathrm{B} 2.1 \mathrm{C}$ & 153 & -28 & 7,1 & -61 & & & & & \\
\hline & & $\mathrm{B} 2.2 \mathrm{~A}$ & 232 & -2 & 9,7 & -38 & & & & & \\
\hline & & $\mathrm{B} 2.2 \mathrm{~B}$ & 195 & -26 & 9,8 & -71 & & & & & \\
\hline & & $\mathrm{B} 2.2 \mathrm{D}$ & 170 & 24 & 21,5 & -43 & & & & & \\
\hline & & $\mathrm{B} 2.3 \mathrm{~A}$ & 195 & -49 & 9,5 & -59 & & & & & \\
\hline & \multirow[t]{6}{*}{ B4 } & B4.1C & 171 & -24 & 19,3 & -77 & 6 & 161,7 & $-22,5$ & 3,6 & -70 \\
\hline & & $\mathrm{B} 4.2 \mathrm{~A}$ & 123 & -13 & 17,6 & 87 & & & & & \\
\hline & & $\mathrm{B} 4.2 \mathrm{C}$ & 124 & 45 & 5,9 & -33 & & & & & \\
\hline & & B4.3B & 161 & -35 & 10,7 & 87 & & & & & \\
\hline & & B4.3C & 197 & -29 & 9,8 & -29 & & & & & \\
\hline & & B4.3D & 201 & -51 & 10,5 & 87 & & & & & \\
\hline DOE & D1 & D1.1C & 162 & -44 & 12,5 & -61 & 3 & 199,3 & $-8,4$ & 2,8 & -71 \\
\hline & & $\mathrm{D} 1.2 \mathrm{C}$ & 223 & 37 & 7,4 & -42 & & & & & \\
\hline & & D1.3A & 206 & -14 & 11 & -64 & & & & & \\
\hline & D2 & $\mathrm{D} 2.1 \mathrm{~A}$ & 207 & 15 & 10,5 & -61 & 4 & 179,3 & $-30,3$ & 4,5 & -76 \\
\hline & & $\mathrm{D} 2.2 \mathrm{~A}$ & 174 & -68 & 11 & -41 & & & & & \\
\hline & & $\mathrm{D} 2.2 \mathrm{D}$ & 156 & -28 & 5,6 & -63 & & & & & \\
\hline & & D2.3A & 175 & -33 & 6,8 & -74 & & & & & \\
\hline & D3 & D3.1A & 170 & -23 & 3,6 & -76 & 11 & 169,5 & $-25,1$ & 73,8 & -75 \\
\hline & & D3.1C & 170 & -17 & 5,4 & -78 & & & & & \\
\hline & & D3.1D & 169 & -19 & 6,6 & -77 & & & & & \\
\hline & & D3.2A & 181 & -39 & 3,4 & -70 & & & & & \\
\hline & & D3.2B & 164 & -24 & 11,1 & -71 & & & & & \\
\hline & & D3.2C & 173 & -27 & 4,2 & -76 & & & & & \\
\hline & & D3.2D & 175 & -21 & 8,1 & -80 & & & & & \\
\hline & & D3.3A & 169 & -36 & 5 & -69 & & & & & \\
\hline & & D3.3B & 170 & -23 & 6,1 & -76 & & & & & \\
\hline & & D3.3C & 172 & -19 & 3,8 & -79 & & & & & \\
\hline & & D3.3D & 152 & -27 & 3,5 & -60 & & & & & \\
\hline & D4 & D4.1A & 218 & -14 & 9,5 & -52 & 1 & 218 & -14 & - & -52 \\
\hline TOLL & $\mathrm{T} 1$ & T1.C & 341 & 42 & 7,7 & 62 & 2 & 351,5 & 389 & 45 & 69 \\
\hline & & T1.A & 1 & 35 & 5,7 & 73 & & & & & \\
\hline & $\mathrm{T} 2$ & T2.A & 359 & 37 & 5,9 & 72 & 3 & 5,5 & 39,1 & 222,6 & 70 \\
\hline & & T2.B & 11 & 42 & 3,6 & 66 & & & & & \\
\hline & & T2.C & 7 & 38 & 0,1 & 70 & & & & & \\
\hline & T3 & T3.A & 11 & 44 & 3,9 & 64 & 4 & 11,5 & 50,4 & 36,8 & 59 \\
\hline & & T3.B & 353 & 49 & 3,8 & 62 & & & & & \\
\hline & & T3.C & 37 & 61 & 4,7 & 38 & & & & & \\
\hline & & T3.D & 12 & 44 & 6,6 & $64 \bigcirc$ & & & & & \\
\hline MRB & M2 & $\mathrm{M} 2.1 \mathrm{~A}$ & 86 & -7 & 24,6 & 4 & 4 & 148,5 & $-50,3$ & 1,4 & -49 \\
\hline & & M2.1D & 156 & -21 & 3,7 & -65 & & & & & \\
\hline & & $\mathrm{M} 2.2 \mathrm{C}$ & 322 & -37 & 9,6 & 46 & & & & & \\
\hline & & $\mathrm{M} 2.3 \mathrm{D}$ & 195 & -23 & 8,2 & -72 & & & & & \\
\hline
\end{tabular}

calculated by considering the average ESR intensities over the three repeated measurements of each aliquot and derived from the Ti-2 function $\left(1 / \mathrm{s}^{2}\right)$. Resulting $\mathrm{D}_{\mathrm{e}}$ values range between $1469 \pm 132$ and $2040 \pm 172$ Gy for section DOE, $1182 \pm 72$ and $1246 \pm 72$ Gy for section MRB, $1441 \pm 42$ and $1479 \pm 85$ Gy for section TOLL as well as $1038 \pm 57$ and $1361 \pm 111$ Gy for section BOU (Table 2).

\subsubsection{De comparison between the different centres}

The $\mathrm{D}_{\mathrm{e}}$ values derived from $\mathrm{Al}$ (EXPLIN) and Ti option D (Ti-2 $\left.1 / \mathrm{s}^{2}\right)$ are mostly $1 \sigma$-consistent $(6$ of $n=11)$. In contrast, the five other samples (C-E3824, C-E3887, C-E3888, C-E3890 and C-E3891) show Ti (option D) $\mathrm{D}_{\mathrm{e}}$ values that are clearly lower compared to those of the Al centre (Table 2), although still consistent at $2 \sigma$. This difference may be the result of incomplete bleaching of the Al centre, given its slower bleaching kinetics compared to that of the Ti centre (Duval et al., 2017). Therefore, based on the principle of the MC ap- proach (Toyoda et al., 2000), the Al signal of samples C-E3825, C-E3826, C-E3884, C-E3885, C-E3886 and C-E3889 may be considered as completely bleached during fluvial transport. Consequently, because both $\mathrm{Ti}$ and $\mathrm{Al}$ centres provide similar $\mathrm{D}_{\mathrm{e}}$ values for these samples, weighted mean $D_{e}$ values were used to estimate combined Al-Ti ESR ages (Table 3). In the case of the five samples resulting in higher $\mathrm{Al} \mathrm{D}_{\mathrm{e}}$ results, we consider the Ti (option $\mathrm{D}$ ) $\mathrm{D}_{\mathrm{e}}$ value as representing the best estimate for the dose absorbed by the sample over time and thus the most suitable for further geomorphological interpretation (Table 3).

\section{3. pIRIR dating of $K$-feldspar}

Due to quartz OSL signal saturation (data not shown), K-feldspars were used for further luminescence analyses. The DRCs of the different pIRIR and associated $\mathrm{IR}_{50}$ signals were best fitted by a SSE func- 
Table 2

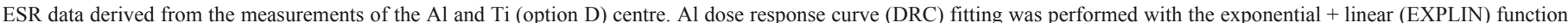

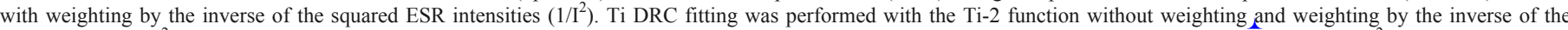

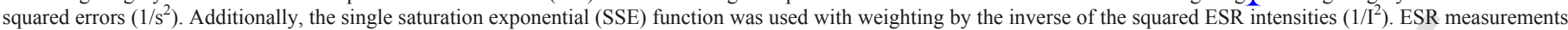

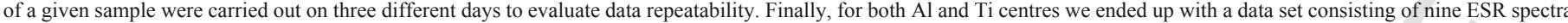

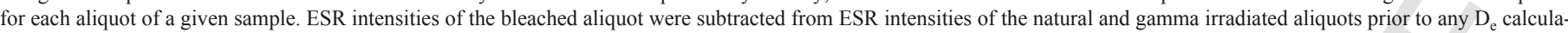

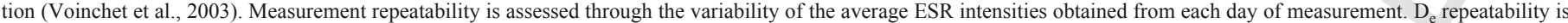
based on the variability of the $\mathrm{D}_{\mathrm{e}}$ values obtained after each day of measurement.

\begin{tabular}{|c|c|c|c|c|c|c|c|c|c|c|c|c|c|}
\hline Centre & $\mathrm{Al}$ & & & & & $\mathrm{Ti}(\mathrm{D})$ & & & & & & & \\
\hline Function & EXPLIN & & & & & Ti-2 & & & & Ti-2 & & SSE & \\
\hline Weighting & $1 / \mathrm{I}^{2}$ & & & & & $1 / \mathrm{s}^{2}$ & & & & EW & & $1 / \mathrm{I}^{2}$ & \\
\hline Sample & $\begin{array}{l}\text { Bleaching } \\
\text { coefficient } \\
(\%)\end{array}$ & $\begin{array}{l}\text { ESR } \\
\text { intensity } \\
\text { precision } \\
(\%)\end{array}$ & $\begin{array}{l}\mathrm{D}_{\mathrm{e}} \\
\text { repeatability } \\
(\%)\end{array}$ & $\begin{array}{l}\mathrm{D}_{\mathrm{e}} \\
(\mathrm{Gy})\end{array}$ & Adj. $r^{2}$ & $\begin{array}{l}\text { ESR } \\
\text { intensity } \\
\text { precision } \\
(\%)\end{array}$ & $\begin{array}{l}\mathrm{D}_{\mathrm{e}} \\
\text { repeatability } \\
(\%)\end{array}$ & Adj. $\mathrm{r}^{2}$ & $\begin{array}{l}\mathrm{D}_{\mathrm{e}} \\
(\mathrm{Gy})\end{array}$ & Adj. $\mathrm{r}^{2}$ & $\begin{array}{l}D_{e} \\
\text { (Gy) }\end{array}$ & Adj. $r^{2}$ & $\begin{array}{l}\mathrm{D}_{\mathrm{e}} \\
(\mathrm{Gy})\end{array}$ \\
\hline C-E3824 & $49 \pm 6$ & 3.3 & 3.6 & $1259 \pm 144$ & 0.9950 & 4.1 & 2.4 & 0.9960 & $1038 \pm 57$ & 0.9964 & $1067 \pm 78$ & 0.9968 & $1027 \pm 61$ \\
\hline C-E3825 & $50 \pm 3$ & 5.3 & 23.2 & $1437 \pm 302$ & 0.9809 & 4.1 & 7.2 & 0.9922 & $1361 \pm 111$ & 0.9955 & $1440 \pm 117$ & 0.9947 & $1282 \pm 99$ \\
\hline C-E3826 & $51 \pm 2$ & 2.2 & 14.5 & $1197 \pm 131$ & 0.9957 & 3.5 & 5.2 & 0.9982 & $1086 \pm 44$ & 0.9973 & $1068 \pm 69$ & 0.9968 & $939 \pm 58$ \\
\hline C-E3884 & $53 \pm 3$ & 4.0 & 11.1 & $1858 \pm 261$ & 0.9943 & 6.8 & 14.6 & 0.9929 & $2040 \pm 172$ & 0.9947 & $2017 \pm 150$ & 0.9891 & $1803 \pm 203$ \\
\hline C-E3885 & $57 \pm 6$ & 2.6 & 5.2 & $1537 \pm 144$ & 0.9971 & 3.3 & 6.0 & 0.9955 & $1469 \pm 132$ & 0.9922 & $1433 \pm 120$ & 0.99465 & $1433 \pm 124$ \\
\hline C-E3886 & $51 \pm 2$ & 1.7 & 9.7 & $1654 \pm 306$ & 0.9885 & 3.5 & 4.9 & 0.9931 & $1643 \pm 134$ & 0.9907 & $1609 \pm 145$ & 0.9857 & $1642 \pm 239$ \\
\hline C-E3887 & $54 \pm 6$ & 1.8 & 7.2 & $2008 \pm 148$ & 0.9982 & 4.6 & 18.1 & 0.9977 & $1441 \pm 42$ & 0.9946 & $1654 \pm 119$ & 0.9987 & $1314 \pm 52$ \\
\hline C-E3888 & $51 \pm 2$ & 3.7 & 12.5 & $1826 \pm 170$ & 0.9970 & 4.9 & 7.3 & 0.9964 & $1479 \pm 85$ & 0.9907 & $1435 \pm 119$ & 0.9939 & $1462 \pm 137$ \\
\hline C-E3889 & $47 \pm 5$ & 4.3 & 2.0 & $1147 \pm 144$ & 0.9947 & 4.2 & 3.9 & 0.9996 & $1246 \pm 72$ & 0.9966 & $1551 \pm 88$ & 0.9974 & $1223 \pm 67$ \\
\hline C-E3890 & $56 \pm 6$ & 6.0 & 3.9 & $1747 \pm 244$ & 0.9933 & 3.9 & 22.1 & 0.9937 & $1200 \pm 105$ & 0.9841 & $1653 \pm 210$ & 0.9923 & $1131 \pm 108$ \\
\hline C-E3891 & $50 \pm 2$ & 2.4 & 9.5 & $1441 \pm 92$ & 0.9987 & 3.8 & 2.8 & 0.9973 & $1182 \pm 72$ & 0.9958 & $1221 \pm 92$ & 0.9951 & $1041 \pm 78$ \\
\hline
\end{tabular}
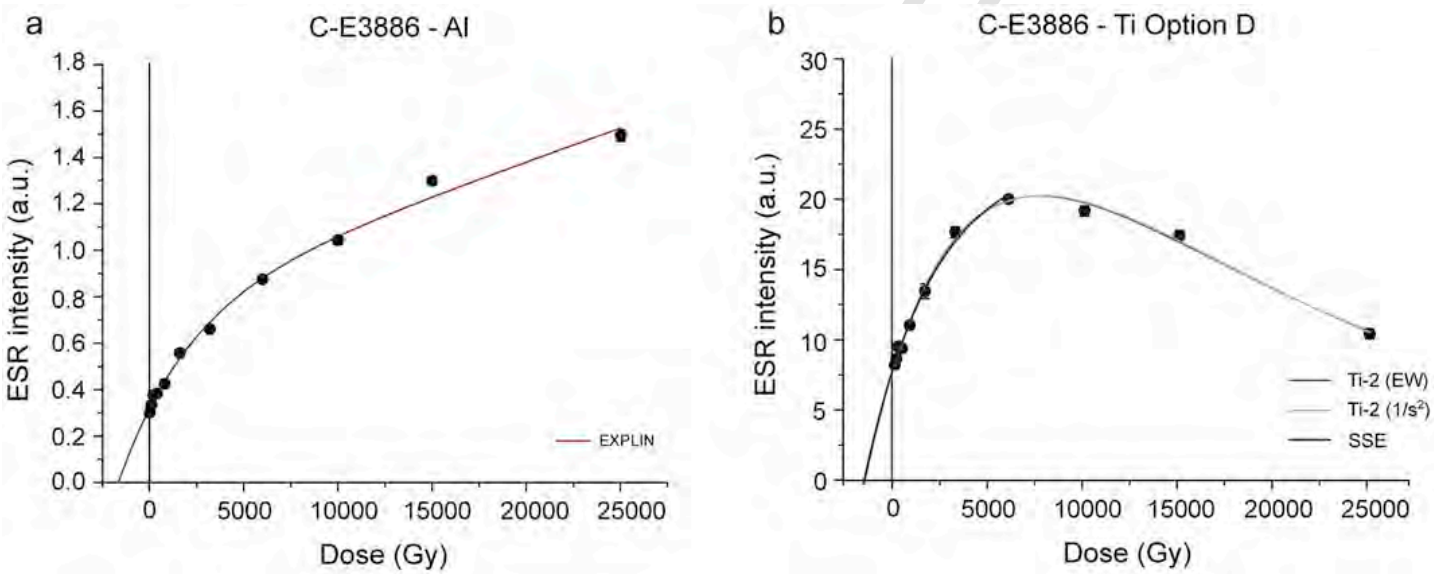

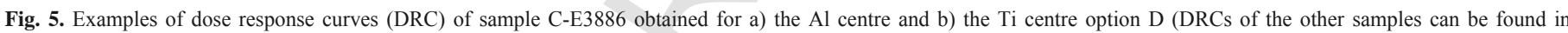
supplementary material Appendix B).

tion. Sensitivity changes could be adequately corrected for and recuperation was $<5 \%$ of the sensitivity-corrected natural signal for all signals measured. We used laboratory fading tests in order to measure sample specific g-values from the $\mathrm{IR}_{50}$ and the two pIR signals (Table 3) which range from $\mathrm{g}_{2 \text { days }}$ of $3.56 \pm 0.59$ to $6.05 \pm 0.79 \% /$ decade $\left(\mathrm{IR}_{50,225}\right)$ and from $1.66 \pm 0.30$ to $2.65 \pm 0.46 \%$ /decade $\left(\mathrm{pIR}_{225}\right)$ as well as from $1.98 \pm 1.80$ to $4.81 \pm 1.26 \%$ /decade $\left(\mathrm{IR}_{50,290}\right)$ and from $0.76 \pm 1.93$ to $2.58 \pm 2.23 \%$ /decade $\left(\mathrm{pIR}_{290}\right)$. Such g-values cannot be interpreted as laboratory artefacts and should be considered as athermal signal loss over geological time scales (Thiel et al., 2011b). The athermal detrapping model of Huntley (2006) as implemented by Kars et al. (2008) was used in order to investigate whether our feldspar samples (C-L3826, C-L3891, C-L3887 and C-L3886) are either in steady-state (i.e., field saturation; Huntley and Lian, 2006) or in disequilibrium which would give further chronometric information. Our calculation of $(\mathrm{n} / \mathrm{N})_{\mathrm{ss}}$ and $(\mathrm{n} / \mathrm{N})$ values for the $\mathrm{pIRIR}_{225}$-and pIRIR 290 -protocols, using both the $\mathrm{IR}_{50}$ and pIR signals, indicates that our samples are either in, or close to, field satura- tion (Fig. 6). Thus, only minimum ages (Table 4) can be derived from the different $\mathrm{IR}_{50}$ and pIR signals based on the faded $2 \mathrm{D}_{0}$ values (Guralnik et al., 2015; Li et al., 2017). Minimum ages vary approximately from 465 to $610 \mathrm{ka}\left(\mathrm{IR}_{50,225}\right)$ and from 410 to $715 \mathrm{ka}$ $\left(\mathrm{pIR}_{225}\right)$ as well as from 345 to $510 \mathrm{ka}\left(\mathrm{IR}_{50,290}\right)$ and from 440 to 610 ka $\left(\mathrm{pIR}_{290}\right)$.

\subsection{Dose rate evaluation}

Radionuclide activity values were determined by HRGS and ICP-MS analysis (Table 3). Both techniques provide consistent results at $1 \sigma$ for $70 \%$ of the samples (24/33), whilst the seven other samples are consistent at $2 \sigma$. Only two activity values vary slightly higher for samples C-E3885 and C-E3886, which might be simply due to sediment heterogeneity, as ICP analyses are carried out on $5 \mathrm{~g}$ of material, vs. $>400 \mathrm{~g}$ for HRGS measurements. No significant radioactive disequilibrium in the uranium decay chain was observed. Overall, when using either HRGS or ICP-MS activity values for calculating 
Table 3

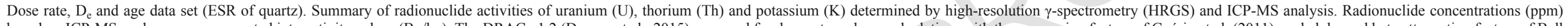

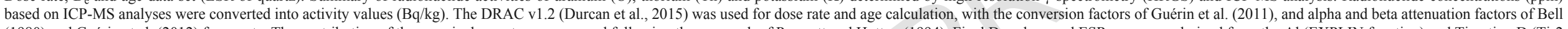

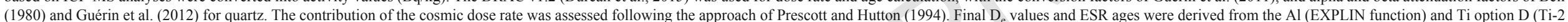

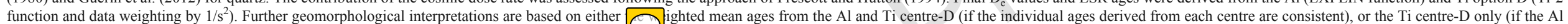

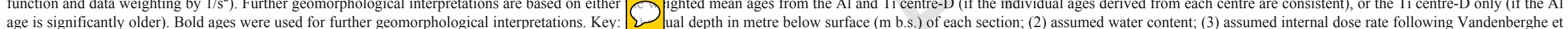
al. (2008); (4) weighted mean $\mathrm{D}_{\mathrm{e}}$ values are calculated only when $\mathrm{Al}$ and Ti ages are consistent at $1 \sigma ;(5)$ based on the weighted mean $\mathrm{D}_{\mathrm{e}}$ values derived from both $\mathrm{Al}$ and Ti centres.

\begin{tabular}{|c|c|c|c|c|c|c|c|c|c|c|c|c|}
\hline Section & Profile & $\mathrm{BOU}$ & & & DOE & & & TOLL & & MRB & & \\
\hline & Sample ID & C-E3824 & C-E3825 & C-E3826 & C-E3884 & C-E3885 & C-E3886 & C-E3887 & C-E3888 & C-E3889 & C-E3890 & C-E3891 \\
\hline \multirow[t]{3}{*}{ Unit } & Grain size $(\mu \mathrm{m})$ & $100-200$ & $100-200$ & $100-200$ & $100-200$ & $100-200$ & $100-200$ & $100-200$ & $100-200$ & $100-200$ & $100-200$ & $100-200$ \\
\hline & Depth (m b.s.) $)^{(1)}$ & 5.3 & 1.5 & 0.5 & 3.2 & 1.9 & 1.2 & 21.4 & 21.6 & 30.0 & 13.8 & 13.4 \\
\hline & Water content (\%) ${ }^{(2)}$ & $15 \pm 5$ & $15 \pm 5$ & $15 \pm 5$ & $15 \pm 5$ & $15 \pm 5$ & $15 \pm 5$ & $15 \pm 5$ & $15 \pm 5$ & $15 \pm 5$ & $15 \pm 5$ & $15 \pm 5$ \\
\hline \multirow[t]{3}{*}{ JRGS } & ${ }^{238} \mathrm{U}(\mathrm{Bq} / \mathrm{kg})$ & $9.33 \pm 0.50$ & $17.16 \pm 0.87$ & $10.70 \pm 0.62$ & $16.04 \pm 0.75$ & $16.17 \pm 0.87$ & $13.80 \pm 0.75$ & $9.70 \pm 0.62$ & $9.45 \pm 0.62$ & $8.45 \pm 0.50$ & $8.58 \pm 0.62$ & $8.21 \pm 0.62$ \\
\hline & ${ }^{232} \mathrm{Th}(\mathrm{Bq} / \mathrm{kg})$ & $6.21 \pm 0.45$ & $11.97 \pm 0.77$ & $8.16 \pm 0.61$ & $13.88 \pm 1.01$ & $13.92 \pm 1.06$ & $11.56 \pm 0.77$ & $13.67 \pm 0.81$ & $13.76 \pm 0.81$ & $11.04 \pm 0.69$ & $10.75 \pm 0.69$ & $9.21 \pm 0.65$ \\
\hline & ${ }^{40} \mathrm{~K}(\%)$ & $0.49 \pm 0.01$ & $0.65 \pm 0.01$ & $0.48 \pm 0.01$ & $0.79 \pm 0.02$ & $0.72 \pm 0.02$ & $0.73 \pm 0.02$ & $0.86 \pm 0.02$ & $0.85 \pm 0.02$ & $0.76 \pm 0.02$ & $0.73 \pm 0.02$ & $0.69 \pm 0.01$ \\
\hline \multirow[t]{2}{*}{ ICP } & ${ }^{238} \mathrm{U}(\mathrm{Bq} / \mathrm{kg})$ & $9.70 \pm 0.92$ & $20.89 \pm 1.12$ & $11.81 \pm 0.95$ & $19.40 \pm 1.09$ & $13.56 \pm 0.98$ & $15.05 \pm 1.00$ & $10.94 \pm 0.94$ & $9.95 \pm 0.92$ & $9.58 \pm 0.92$ & $8.46 \pm 0.90$ & $9.33 \pm 0.91$ \\
\hline & ${ }^{232} \mathrm{Th}(\mathrm{Bq} / \mathrm{kg})$ & $8.72 \pm 0.41$ & $12.13 \pm 0.54$ & $9.78 \pm 0.45$ & $14.57 \pm 0.64$ & $11.56 \pm 0.52$ & $14.61 \pm 0.64$ & $14.28 \pm 0.63$ & $13.35 \pm 0.59$ & $11.20 \pm 0.51$ & $10.83 \pm 0.49$ & $10.55 \pm 0.48$ \\
\hline \multirow[t]{6}{*}{ Dose rate } & Internal $(\mathrm{Gy} / \mathrm{ka})^{(3)}$ & $0.05 \pm 0.03$ & $0.05 \pm 0.03$ & $0.05 \pm 0.03$ & $0.05 \pm 0.03$ & $0.05 \pm 0.03$ & $0.05 \pm 0.03$ & $0.05 \pm 0.03$ & $0.05 \pm 0.03$ & $0.05 \pm 0.03$ & $0.05 \pm 0.03$ & $0.05 \pm 0.03$ \\
\hline & External alpha (Gy/ka) & $0.01 \pm 0.01$ & $0.03 \pm 0.02$ & $0.02 \pm 0.02$ & $0.03 \pm 0.03$ & $0.03 \pm 0.02$ & $0.02 \pm 0.02$ & $0.02 \pm 0.02$ & $0.02 \pm 0.02$ & $0.02 \pm 0.02$ & $0.02 \pm 0.01$ & $0.02 \pm 0.01$ \\
\hline & External beta (Gy/ka) & $0.41 \pm 0.02$ & $0.60 \pm 0.04$ & $0.42 \pm 0.03$ & $0.69 \pm 0.04$ & $0.64 \pm 0.04$ & $0.62 \pm 0.04$ & $0.68 \pm 0.04$ & $0.67 \pm 0.04$ & $0.60 \pm 0.04$ & $0.58 \pm 0.04$ & $0.54 \pm 0.03$ \\
\hline & External gamma (Gy/ka) & $0.24 \pm 0.01$ & $0.39 \pm 0.02$ & $0.27 \pm 0.02$ & $0.43 \pm 0.03$ & $0.42 \pm 0.02$ & $0.38 \pm 0.02$ & $0.40 \pm 0.02$ & $0.39 \pm 0.02$ & $0.33 \pm 0.02$ & $0.33 \pm 0.02$ & $0.30 \pm 0.02$ \\
\hline & Cosmic $(\mathrm{Gy} / \mathrm{ka})$ & $0.11 \pm 0.01$ & $0.17 \pm 0.02$ & $0.21 \pm 0.02$ & $0.14 \pm 0.01$ & $0.16 \pm 0.02$ & $0.18 \pm 0.02$ & $0.03 \pm 0.003$ & $0.03 \pm 0.003$ & $0.02 \pm 0.002$ & $0.05 \pm 0.005$ & $0.05 \pm 0.005$ \\
\hline & Total (Gy/ka) & $0.82 \pm 0.04$ & $1.24 \pm 0.06$ & $0.97 \pm 0.05$ & $1.34 \pm 0.06$ & $1.31 \pm 0.06$ & $1.25 \pm 0.06$ & $1.18 \pm 0.06$ & $1.17 \pm 0.06$ & $1.02 \pm 0.05$ & $1.02 \pm 0.05$ & $0.96 \pm 0.05$ \\
\hline \multirow[t]{3}{*}{$D_{e}$ values } & $\mathrm{Al}$ centre (Gy) & $1259 \pm 144$ & $1437 \pm 302$ & $1197 \pm 131$ & $1858 \pm 261$ & $1537 \pm 144$ & $1654 \pm 306$ & $2008 \pm 148$ & $1826 \pm 170$ & $1147 \pm 144$ & $1747 \pm 244$ & $1441 \pm 92$ \\
\hline & Ti centre-D (Gy) & $1038 \pm 57$ & $1361 \pm 111$ & $\mathrm{C} 1086 \pm 44$ & $2040 \pm 172$ & $1469 \pm 132$ & $1643 \pm 134$ & $1441 \pm 42$ & $1479 \pm 85$ & $1246 \pm 72$ & $1200 \pm 105$ & $1182 \pm 72$ \\
\hline & Weighted mean $\mathrm{Al}$ and $\mathrm{Ti}$ centre-D $(\mathrm{Gy})^{(4)}$ & - & $1370 \pm 125$ & $1097 \pm 69$ & $1985 \pm 175$ & $1500 \pm 123$ & $1645 \pm 148$ & - & - & $1226 \pm 89$ & - & - \\
\hline \multirow[t]{2}{*}{ Age } & $\mathrm{Al}$ centre $(\mathrm{Ma})$ & $1.53 \pm 0.19$ & $1.16 \pm 0.25$ & $1.24 \pm 0.15$ & $1.39 \pm 0.21$ & $1.18 \pm 0.12$ & $1.32 \pm 0.25$ & $1.70 \pm 0.15$ & $1.57 \pm 0.17$ & $1.12 \pm 0.15$ & $1.70 \pm 0.25$ & $1.50 \pm 0.12$ \\
\hline & Ficentre $\mathrm{B}(\mathrm{Ma})$ & $1.26 \pm 0.10$ & $1.10 \pm 0.10$ & $1.12 \pm 0.07$ & $1.53 \pm 0.15$ & $1.13 \pm 0.12$ & $1.31 \pm 0.12$ & $1.22 \pm 0.07$ & $1.27 \pm 0.10$ & $1.22 \pm 0.10$ & $1.17 \pm 0.12$ & $1.23 \pm 0.10$ \\
\hline
\end{tabular}



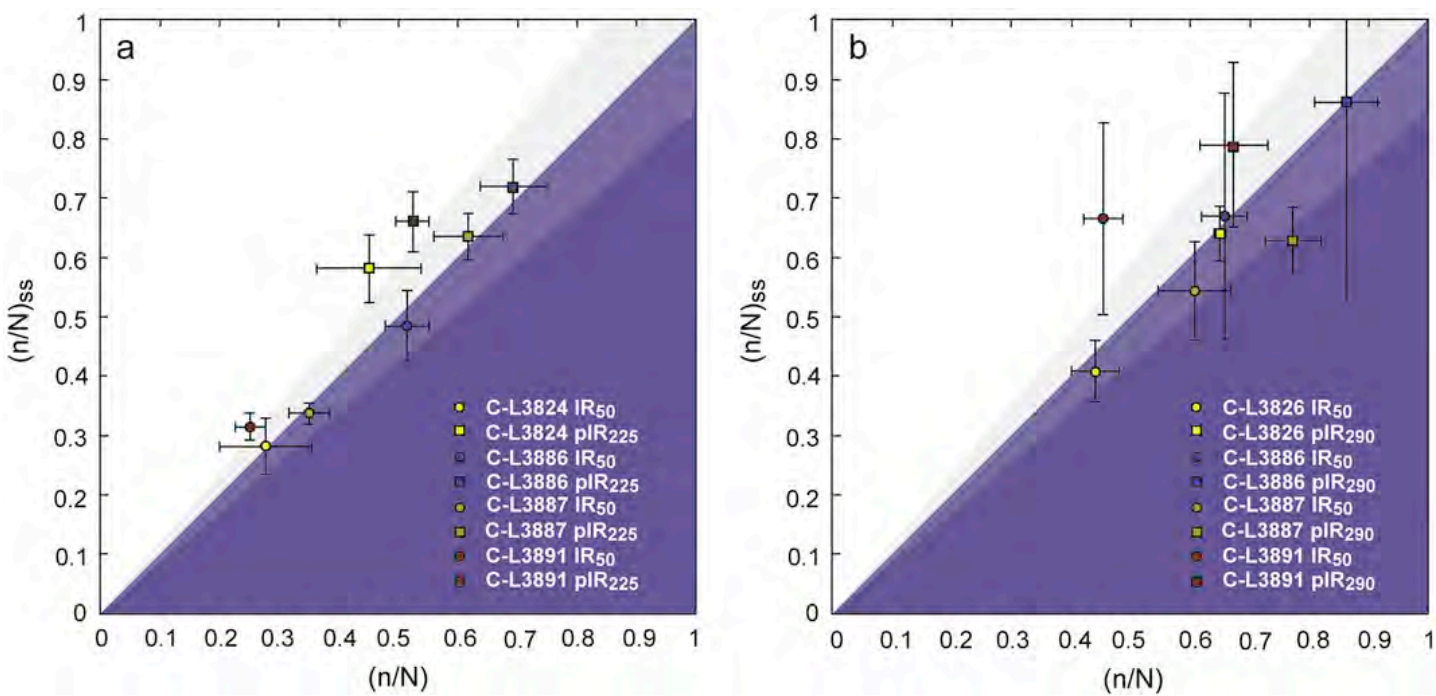

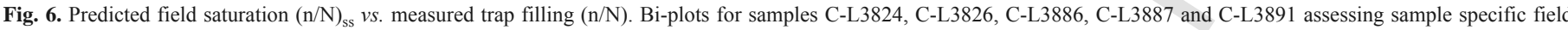

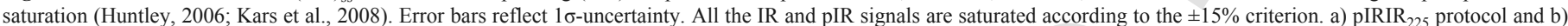
pIRIR $_{290}$ protocol. The large uncertainties in the $\mathrm{IR}_{50}$ and $\mathrm{pIR}_{290}$ of the $(\mathrm{n} / \mathrm{N})_{\mathrm{ss}}$ values originated from the high level of scatter in fading measurements.

Table 4

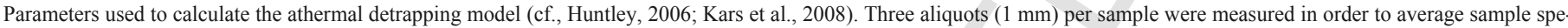

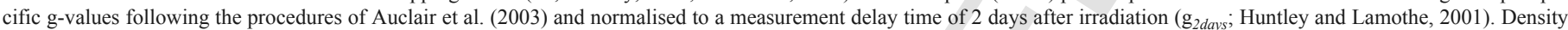

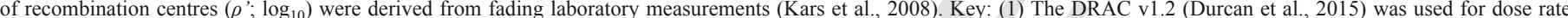

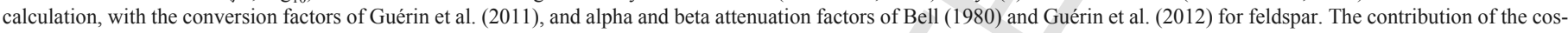

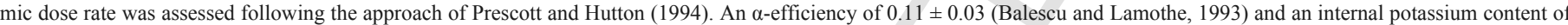

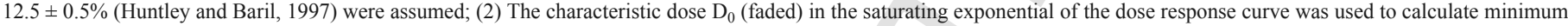
ages for both $\mathrm{IR}_{50}$ and pIR signals (based on $2 \mathrm{D}_{0}$ ).

\begin{tabular}{|c|c|c|c|c|c|c|c|c|}
\hline Protocol & Profile & Sample ID & IRSL signal & $\begin{array}{l}\mathrm{g}_{2 \text { days }} \\
(\% / \text { decade })\end{array}$ & $\rho^{\prime}$ & $\begin{array}{l}\mathrm{D}_{0} \\
\text { (Gy) }\end{array}$ & $\begin{array}{l}\text { Total } \\
\text { dose rate }{ }^{(1)} \\
(\mathrm{Gy} / \mathrm{ka})\end{array}$ & $\begin{array}{l}\text { Minimum age } \\
(\mathrm{ka})\end{array}$ \\
\hline \multirow[t]{8}{*}{$\mathrm{pIRIR}_{225}$} & $\mathrm{BOU}$ & C-L3824 & $\mathrm{IR}_{50}$ & $6.05 \pm 0.79$ & $-5.35 \pm 0.06$ & 405 & $1.35 \pm 0.19$ & 599 \\
\hline & $\mathrm{BOU}$ & C-L3824 & $\mathrm{pIR}_{225}$ & $2.65 \pm 0.46$ & $-5.73 \pm 0.08$ & 483 & $1.35 \pm 0.19$ & 714 \\
\hline & DOE & C-L3886 & $\mathrm{IR}_{50}$ & $3.56 \pm 0.59$ & $-5.59 \pm 0.07$ & 419 & $1.81 \pm 0.19$ & 463 \\
\hline & DOE & C-L3886 & $\mathrm{pIR}_{225}$ & $1.66 \pm 0.30$ & $-5.93 \pm 0.08$ & 369 & $1.81 \pm 0.19$ & 407 \\
\hline & TOLL & C-L3887 & $\mathrm{IR}_{50}$ & $5.25 \pm 0.26$ & $-5.42 \pm 0.02$ & 476 & $1.73 \pm 0.19$ & 551 \\
\hline & TOLL & C-L3887 & $\mathrm{pIR}_{225}$ & $2.26 \pm 0.30$ & $-5.80 \pm 0.06$ & 452 & $1.73 \pm 0.19$ & 523 \\
\hline & MRB & C-L3891 & $\mathrm{IR}_{50}$ & $5.61 \pm 0.36$ & $-5.39 \pm 0.03$ & 454 & $1.50 \pm 0.20$ & 607 \\
\hline & MRB & C-L3891 & $\mathrm{pIR}_{225}$ & $2.06 \pm 0.36$ & $-5.84 \pm 0.08$ & 452 & $1.50 \pm 0.20$ & 604 \\
\hline \multirow[t]{8}{*}{ pIRIR $_{290}$} & $\mathrm{BOU}$ & C-L3826 & $\mathrm{IR}_{50}$ & $4.81 \pm 1.26$ & $-5.48 \pm 0.11$ & 362 & $1.51 \pm 0.19$ & 480 \\
\hline & BOU & C-L3826 & $\mathrm{pIR}_{290}$ & $2.58 \pm 2.23$ & $-5.76 \pm 0.37$ & 425 & $1.51 \pm 0.19$ & 564 \\
\hline & DOE & C-L3886 & $\mathrm{IR}_{50}$ & $1.98 \pm 1.80$ & $-5.85 \pm 0.39$ & 366 & $1.81 \pm 0.19$ & 404 \\
\hline & DOE & C-L3886 & $\mathrm{pIR}_{290}$ & $0.76 \pm 1.93$ & $-6.29 \pm 1.10$ & 399 & $1.81 \pm 0.19$ & 440 \\
\hline & TOLL & C-L3887 & $\mathrm{IR}_{50}$ & $3.01 \pm 0.77$ & $-5.66 \pm 0.11$ & 297 & $1.73 \pm 0.19$ & 344 \\
\hline & TOLL & C-L3887 & $\mathrm{pIR}_{290}$ & $2.23 \pm 1.10$ & $-5.79 \pm 0.21$ & 386 & $1.73 \pm 0.19$ & 447 \\
\hline & MRB & C-L3891 & $\mathrm{IR}_{50}$ & $2.07 \pm 1.26$ & $-5.84 \pm 0.26$ & 378 & $1.50 \pm 0.20$ & 506 \\
\hline & MRB & C-L3891 & $\mathrm{pIR}_{290}$ & $1.18 \pm 0.85$ & $-6.09 \pm 0.31$ & 454 & $1.50 \pm 0.20$ & 607 \\
\hline
\end{tabular}

total dose rates, all ESR ages remain within a $1 \sigma$-error range (supplementary material; Appendix C Fig. C1). Therefore, total dose rates were calculated based on HRGS (Table 3 ). The thickness of overburden varies between 0.5 and $30 \mathrm{~m}$ b.s. giving a contribution of the cosmic dose rate to the total dose rate between $\sim 21$ and $\sim 2 \%$, respectively. The contribution of the beta and gamma dose rates to the total dose rate varies between 43 and $58 \%$ as well as 27 and 33\%, respectively.

\subsection{Chronostratigraphy}

Screening the IRSL signals for field saturation (Huntley, 2006; Kars et al., 2008, Fig. 6), shows that all feldspar samples are saturated, suggesting fluvial aggradation of the lower Moulouya River at least as early as the Middle Pleistocene (Table 4). Measured water contents vary between 2 and $15 \%$. Since sampling was carried out during a dry spring/summer season, the measured water contents probably underestimate the true water contents. Therefore, we considered a water content of $15 \pm 5 \%$ as a reasonable estimate for calculating the final ESR ages. This large associated error (30\% relative 1 sigma uncertainty) was assumed to encompass short- and long-term variations in the water content. If considering $25 \%$ of water content instead, the resulting age estimates increase by $\sim 10 \%$ on average, but nevertheless remain within 1 sigma uncertainty (supplementary material; Appendix C Fig. C2).

ESR ages are stratigraphically consistent at $2 \sigma$ within each terrace section (Fig. 7). In combination with the palaeomagnetic analyses, 


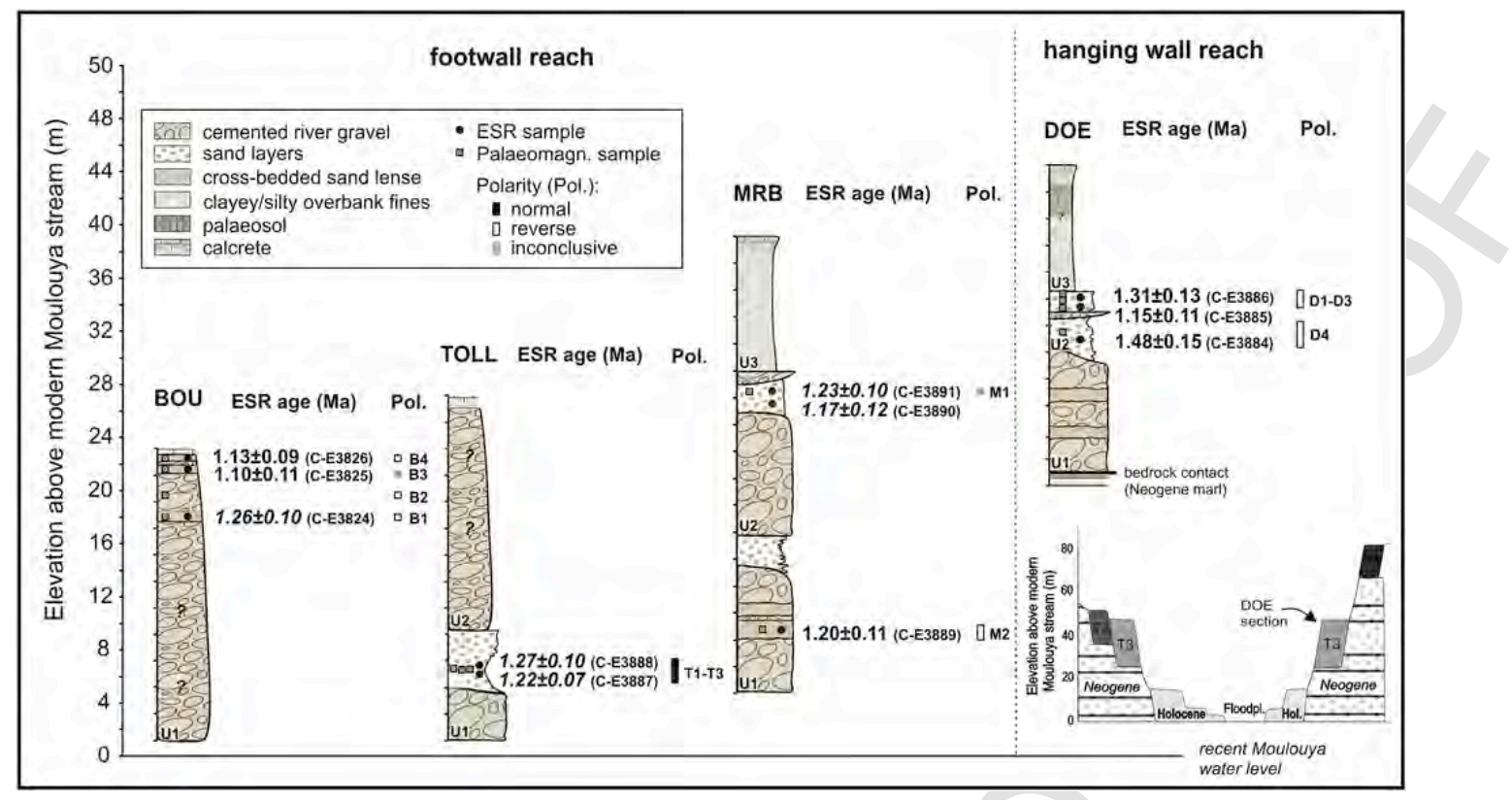

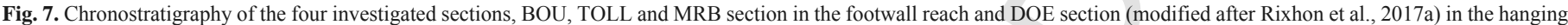

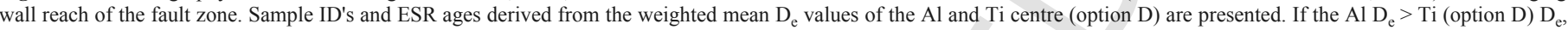
then the Ti (option D) ESR age is shown (in italics). Palaeomagnetic polarities (Pol.) are shown as black (normal), white (reverse) and gray (inconclusive) bars.

these new data provide the first chronological framework for the evolution of the Moulouya terraces during Calabrian times.

Regarding the uppermost part of the BOU section (Fig. 7), ESR ages are stratigraphically consistent: the lowermost sample yields a somewhat older age of $1.26 \pm 0.10 \mathrm{Ma}(\mathrm{C}-\mathrm{E} 3824)$ compared to the two samples from the upper part which provide two close ages of $1.10 \pm 0.11 \mathrm{Ma}(\mathrm{C}-\mathrm{E} 3825)$ and $1.13 \pm 0.09$ (C-E3826). These results clearly indicate a Calabrian chronology for the deposits which is consistent with the reversed magnetic polarities identified at this section.

Similarly, the MRB section (Fig. 7) reveals a deposition age of $1.20 \pm 0.11 \mathrm{Ma}(\mathrm{C}-\mathrm{E} 3889)$ in its lowermost unit 1, which is in good agreement with the reverse polarity given from the palaeomagnetic results, and indicating thus a Matuyama age $(>0.78 \mathrm{Ma}$; Gradstein et al., 2012). In contrast, palaeomagnetic analyses of the upper part of unit 2 in the MRB section did not provide conclusive results, but highly consistent burial ESR ages of $1.17 \pm 0.12$ (C-E3890) and $1.23 \pm 0.10 \mathrm{Ma}$ (C-E3891) indicate that aggradation took place during similar time periods.

The unit 2 of the DOE section (Fig. 7) dates back to $1.48 \pm 0.15$ (C-E3884), $1.15 \pm 0.11$ (C-E3885) and $1.31 \pm 0.13 \mathrm{Ma}(\mathrm{C}-\mathrm{E} 3886)$, from the lower to the upper sample, respectively. The slight scatter of those ESR ages (12.7\%) may be partially explained by the heterogeneity of the depositional context which is displayed in gravel-dominated deposits (unit 2: channel-like structure at $11.5 \mathrm{~m}$ b.s.; Fig. 3i). In the absence of in situ gamma measurements, it is possible that the gamma dose rate derived from laboratory measurements might not fully reflect the actual sediment structure of unit 2 in the DOE section for some of the samples, inducing thus some age scatter. However, the three ESR samples unambiguously indicate chronologies $>1 \mathrm{Ma}$, i.e., in excellent agreement with the reversed polarities identified within the unit 2. Similarly to the BOU and MRB sections, the DOE section indicates fluvial aggradation during the Matuyama chron as well. However, so far the question remains open whether the DOE section correspond to the terraces in the footwall reach.

In comparison, section TOLL (Fig. 7) presents somewhat more contrasted results. Two highly consistent burial ESR ages of
$1.27 \pm 0.10$ (C-E3888) and 1.22 $\pm 0.07 \mathrm{Ma}$ (C-E3887) were obtained, indicating thus a chronology similar to those of the other sections. However, the corresponding palaeomagnetic study provides a normal polarity for those deposits. Given the excellent consistency between ESR and palaeomagnetic results obtained for the other sections, the possibility of a Brunhes chronology for those deposits may be reasonably discarded. Taking into account the ESR age errors, it seems instead that the deposits are more likely correlated to a normal polarity subchron like Jaramillo (1.05-1.00 Ma) or Cobb Mountain (1.22-1.19 Ma) (Singer, 2014) within the Matuyama chron, with some preferences for the former as it covers a longer time range.

\section{Pleistocene evolution of the lower Moulouya}

Although several recent studies dealing with the Moulouya catchment provided new answers to various questions related to the geosciences, i.e., geomorphology and sedimentology (e.g., Rixhon et al., 2017a), hydrogeology (e.g., Sardinha et al., 2012), morphometry (e.g., Barcos et al., 2014), stratigraphy (e.g., Sani et al., 2000) and tectonics (e.g., Pastor et al., 2015), the timing and a synthesis of these observations has not yet been reported. This is especially true concerning the hydrological link between the Guercif and the Triffa basins, located up- and downstream of the Beni Snassen massif gorge, respectively (Fig. 8a). Based on our observations and the newly established chronological framework, we tentatively present a first reconstruction of the Pleistocene evolution of the lower course of the Moulouya. We must, however, bear in mind that the existing information is provided at different temporal and spatial scales and thereby hampers a high-resolution reconstruction. Before achieving this goal, we must also critically assess the significance of the chronostratigraphical framework based on the fluvial archives and discuss it at the local scale, for instance with respect to the newly identified thrusting (Rixhon et al., 2017a). 


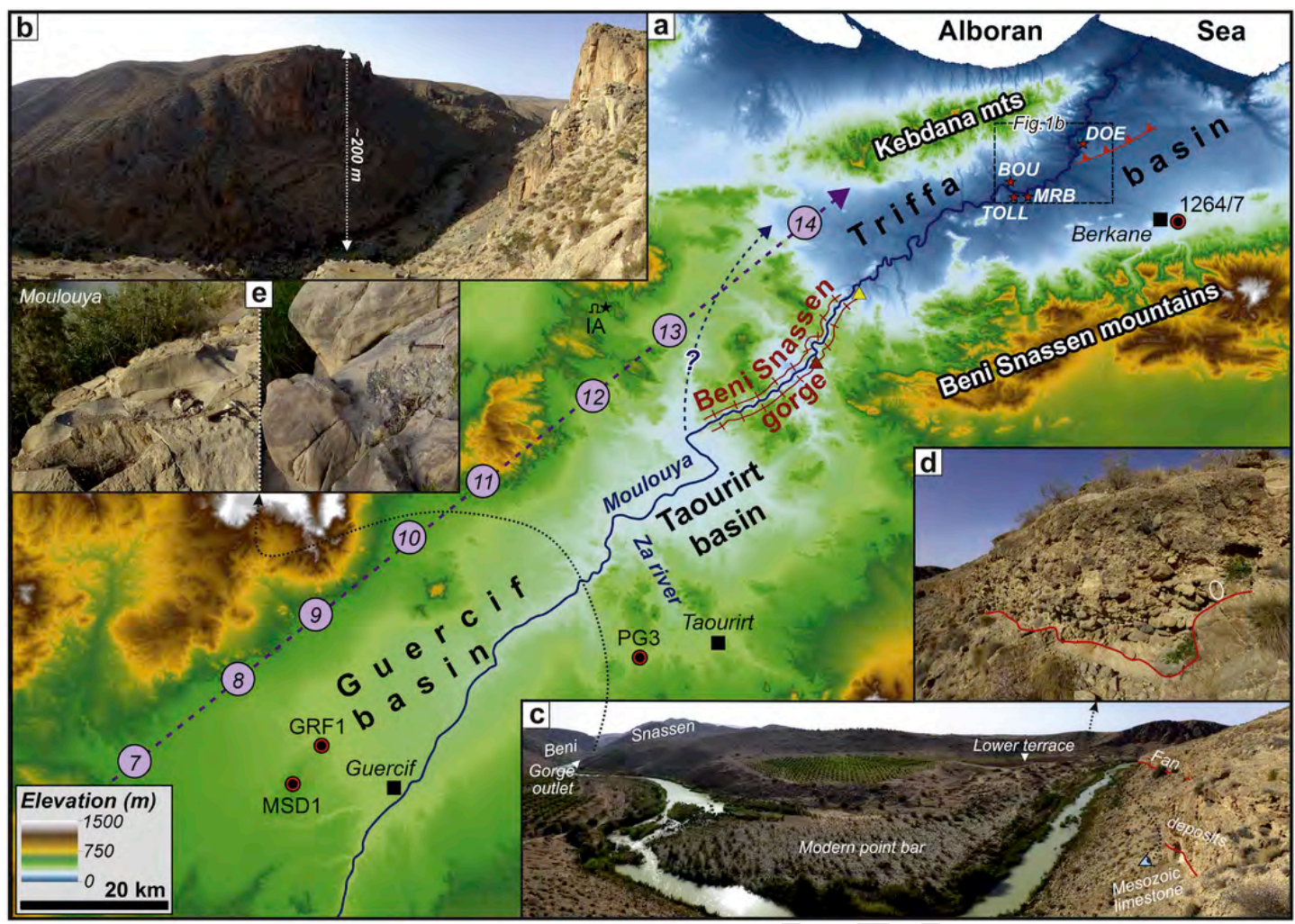

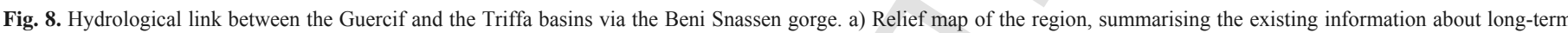

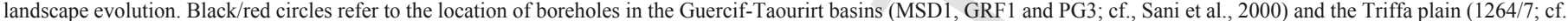

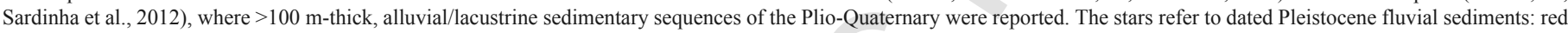

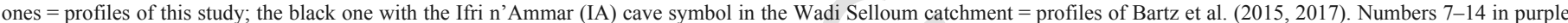

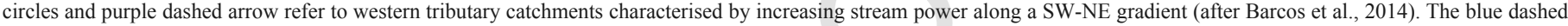

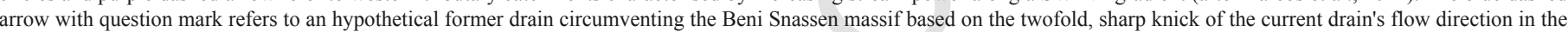

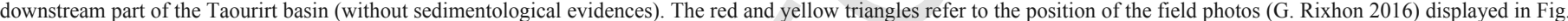

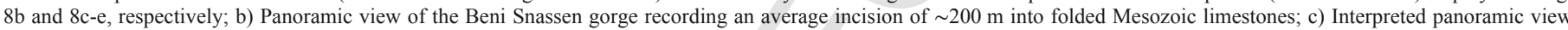

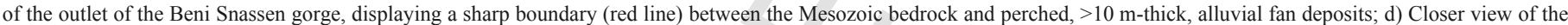

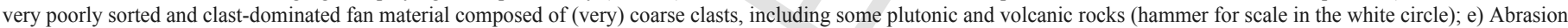

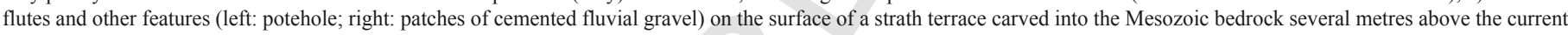
drain at the gorge outlet (hammer for scale). (For interpretation of the references to colour in this figure legend, the reader is referred to the web version of this article.)

\subsection{Pleistocene fluvial evolution of the Triffa basin}

\subsubsection{Calabrian deposition vs. absence of Middle/Late Pleistocene sediments}

In addition to the remarkable concordance between the results of ESR dating and palaeomagnetism, the most striking outcome of this study is that all ESR ages indicate massive fluvial deposition during the end of the Calabrian. While $\sim 1.5$ Ma represents the oldest age found in the DOE section, a large majority of ages cluster around 1.1-1.3 Ma. No numerical age is younger than $1 \mathrm{Ma}$ (Fig. 7), and it seems quite unlikely that fluvial deposition has also occurred during the Middle Pleistocene despite the normal polarity identified in the TOLL profile. Given the massive aggradation recorded in the footwall reach (Rixhon et al., 2017a), Middle and Late Pleistocene sediments, if any, should be found in the uppermost part of the fluvial sequences. This assertion contradicts our $1.10 \pm 0.11-1.26 \pm 0.10$ Ma ESR ages in the BOU profile (all three in the very upper part of the sequence and all confirmed by a reverse polarity) and the $1.17 \pm 0.12-1.23 \pm 0.10 \mathrm{Ma}$ ESR ages in the MRB profile (the two upper ones). We thus assume that the complete hypothetical removal of the Middle and Late Pleistocene deposits over an unknown times- pan appears unlikely and that the latter are virtually absent in this river reach. In the hanging wall reach, no cemented terrace sediments are observed between the Calabrian T3, i.e., the lowermost Pleistocene level in the terrace staircase (Fig. 2c), and the present-day valley bottom characterised by a Holocene infill (Rixhon et al., 2017a). This also points to the absence of terrace formation during the Middle and Late Pleistocene.

In large river systems, cyclic fluvial aggradation and entrenchment episodes were largely interpreted as a response to Quaternary climatic fluctuations, especially since the Mid Pleistocene revolution (e.g., Bridgland and Westaway, 2008). This cyclic imprint was also largely recognised in other Moroccan catchments or those draining the Iberian Peninsula. A tight correlation between 100 ka-climatic cycles and terrace formation in the Dadès valley, which drains the Ouarzazate basin in southern Morocco, was proposed (Stokes et al., 2017). The same holds for smaller systems in the Ouarzazate basin: formation of terraces and alluvial fans is firstly modulated by these climatic cycles and spans at least for glacial/interglacial cycles (Arboleya et al., 2008). Large and well-studied catchments draining the Iberian Peninsula (i.e., Duero, Ebro, Guadalquivir and Tajo) display well-preserved terrace staircases, whose formation is closely related to climatic oscillations (e.g., Santisteban and Schulte, 2007; 
Cunha et al., 2017). By contrast, the seemingly exclusive Calabrian fluvial record in the lowermost sedimentary basin of the Moulouya in NE Morocco strongly points to an acyclic and highly discontinuous sedimentation pattern during the second half of the Quaternary. We therefore suggest that the postulated absence of Middle and Late Pleistocene deposits from our sedimentary record seems to rule out climate as the main driver for long-term fluvial evolution of the lower Moulouya. This absence, if confirmed, would also imply low sediment connectivity between erosional areas (Beni Snassen, Kebdana Mountains) and the main drain in the Triffa plain (Fig. 2a and b). OSL/ pIRIR dating of ephemeral stream sediments in the Wadi Selloum, a first-order western tributary of the Moulouya (identified by the no. 13 and the symbol IA in Fig. 8a), seems confirming large delays in sediment transport within the catchment: while Late Pleistocene sediments (from MIS 5c to MIS 2; Bartz et al., 2015, 2017) were found in the tributary, these are so far not observed in the main trunk.

\subsubsection{Quaternary crustal deformation related to thrusting}

The well-preserved terrace flight in the hanging wall reach, comprising three terrace levels (from the highest to the lowest: T1, T2 and T3; Fig. 2c), bears witness to thrusting activity in the Triffa basin during the Pleistocene (Rixhon et al., 2017a). Fluvial deposition in the DOE profile (T3) is dated to $\sim 1.5$ and $\sim 1.3 \mathrm{Ma}$ (C-E3884-3886). Given the relative elevation of this terrace, this implies incision rates of $0.025 \pm 0.003 \mathrm{~mm} / \mathrm{a}$ since terrace abandonment. While thrusting was thus active during the Calabrian, the apparent lack of cemented terrace sediments between T3 and the present-day valley bottom seems to indicate that motion along the thrust zone was reduced during Middle and Late Pleistocene. Note that similar minimum long-term incision rates of $0.035 \mathrm{~mm} / \mathrm{a}$ have been observed in the Oued Amekrane in the northern Rif mountains (Barcos et al., 2014). By contrast, incision rates based on cosmogenic nuclide dating of fan terraces in a Moulouya tributary debouching into the Missour basin (Fig. 1) amounted to $\sim 0.3-0.4 \mathrm{~mm} / \mathrm{a}$ since the Middle Pleistocene (Pastor et al., 2015). While we must bear in mind that this last region was affected by strong and generalised mantle-driven uplift over the Pleistocene, locally accentuated by crustal shortening of the Middle Atlas (Pastor et al., 2015), this also reveals contrasting incisional behaviours along the successive Moulouya reaches.

\subsection{Hydrological link between the Guercif and Triffa basins}

\subsubsection{Late Neogene: disconnected basins}

During the Messinian, sporadic connection between the Guercif Neogene foreland basin and the Atlantic Ocean via the Taza corridor may have occurred, but the drop in sea-level related to the Messinian event was seemingly not recorded (Bouazza et al., 2009). At the end of the Messinian and the beginning of the Pliocene, long-lasting, massive endorheic deposition of the main trunk and related fan deposition from the tributaries draining the neighbouring massifs is suggested to have taken place in the northern part of the Guercif basin and the Taourirt basin (Bouazza et al., 2009). This is in good agreement with thick, terrestrial sedimentary sequences of the Pliocene and Pleistocene, reported both in the Triffa plain (up to $150 \mathrm{~m}$-thick lacustrine/alluvial sequence, Sardinha et al., 2012, Fig. 8a) and the Guercif basin (up to $600 \mathrm{~m}$ of alluvial conglomerates, calcarenites and occasional lacustrine deposits, Sani et al., 2000, Fig. 8a). Moreover, as for the Guercif basin, a shift from net aggradation during the Miocene-Pliocene to net incision at the very end of the Pliocene-Quaternary, punctuated by alluvial fan deposition, probably occurred in the Moulouya system (Pastor et al., 2015). The hydrological dis- connection between both basins during the Late Neogene agrees well with outcomes of independent tectonic studies: N-S compressive shortening has dominated the geodynamic behaviour of NE Morocco from the Miocene to the Quaternary onwards. While shortening rates of $1-2.3 \mathrm{~mm} / \mathrm{a}$ were suggested in the Rif mountains (Meghraoui et al., 1996), these compressive stresses lead to continuous uplift of the Atlas mountains (Ait Brahim et al., 2002), including the Beni Snassen massif (Barcos et al., 2014).

\subsubsection{Quaternary: formation of the current Moulouya drain through river piracy?}

The $\sim 30 \mathrm{~km}$-long Beni Snassen gorge records an average incision of $\sim 200 \mathrm{~m}$ (up to $300 \mathrm{~m}$-deep) into the folded Mesozoic limestones of the massif (Fig. 8b), and the river long profile in this reach displays a clear knickzone (Barcos et al., 2014; Rixhon et al., 2017a). Given the aforementioned arguments, it appears unlikely that the formation of this gorge is pre-Quaternary and occurred through superimposition. As rock uplift of the Beni Snassen massif seemingly outpaced the incision potential of the former upper Moulouya drainage, as suggested by long-lasting fluvial aggradation, antecedence is doubtful too. Bouazza et al. (2009) have proposed a third explanation: a series of capture events at the onset of the Quaternary triggered incision of the Moulouya through the Beni Snassen. According to Stokes and Mather (2003), a headward-migrating and actively incising river, cutting back into and across an uplifting massif, is needed to create a transverse drainage system, that is, in our case, the Beni Snassen gorge. In order to counterbalance rock uplift in the homonymous massif, a steep, former stream originating in the Beni Snassen and debouching into the Triffa basin (i.e., "palaeo-lower Moulouya"), hence characterised by a high stream power, could have captured the Guercif basin through headward migration. However, while Bouazza et al. (2009) failed to provide any convincing data, this assumption should be anew considered with respect to our new results and observations. Three main lines of argument are in favour of piracy and basin capture: (i) in the lowermost reach of the Moulouya in the Guercif basin (nowadays dammed), the current drain's flow direction exhibits a twofold, sharp knick within $\sim 10 \mathrm{~km}$ (Fig. 8a): SW- NNW first and NNW-NE at the very foot slopes of the Beni Snassen. Interestingly, in the direct northward prolongation of the second knick, a low-lying ( $<350 \mathrm{~m}$ a.s.l.) and relatively flat area, filled with Neogene and Quaternary sediments (Fig. 2a), stretches along a S-N direction and is connected to the Triffa basin via the Zebra plain. If any linkage between the Guercif and Triffa basins should have existed before the current one, one may expect that the Moulouya had circumvented the Beni Snassen massif along this corridor (see arrow on Fig. 8a). This typical "elbow" morphology points to a capture event (e.g., Le Roux and Harmand, 1998), although this hypothesis must be confirmed by sedimentological evidences; (ii) a large, several km-long, fan morphology occurs at the outlet of the Beni Snassen gorge (Fig. 8c). Located several tens of metres above the present-day channel, very poorly sorted, $>10$ m-thick fan deposits are primarily composed of coarse to very coarse clasts (a few boulders $>50 \mathrm{~cm}$ in size; Fig. 8d). Although no clast lithological analysis could be performed here because of the highly-indurated sediment, some plutonic (i.e., granite) and volcanic (i.e., basalt) pebbles were observed amongst the gravels. Both are completely absent from the western part of the Beni Snassen (Fig. 2a), which has been incised by the Moulouya and its local tributaries. An upstream provenance for the magmatic clasts must be thus considered: either from the reliefs surrounding the Guercif and Taourirt basins (Fig. 2a) or from the larger Paleozoic Aouli batholith located in the upper Moulouya reach (Pastor et al., 2015; Rixhon et al., 2017a), thereby implying a long 
transport distance. Given its morphology and position well above the current river as well as its sedimentological features, we assume that this fan documents the first hydrological connection between the Guercif and the Triffa basins through the uplifting Beni Snassen. This points to a capture event and agrees well with the occurrence of such fan structures at the outlet of the Río Almanzora transverse drainage in south-eastern Spain (southern foot slopes of the Sierra Almagro), most probably related to a stream piracy (Stokes and Mather, 2003); (iii) morphometric indicators show that the whole Moulouya catchment is in disequilibrium over a long timescale (Barcos et al., 2014). Stream length-gradient analysis, which highlights changes in stream power along river reaches (Pérez-Peña et al., 2009), shows several anomalies along the main trunk and peak values of stream length-gradient are documented in the Beni Snassen gorge (Barcos et al., 2014). This in good agreement with a well pronounced knickzone along this reach (Pastor et al., 2015) and a SW-NE gradient of stream power increase observed in western tributaries located upstream (no. 7-13) and downstream (no. 14) of the Beni Snassen gorge (Fig. 8a; Barcos et al., 2014). All these observations point to transient fluvial response to major disturbance that occurred during the Quaternary along the Beni Snassen reach and agrees well with the capture hypothesis.

As for the age of the postulated piracy event, our chronological framework for fluvial deposition in the Triffa basin provides insightful information. In particular, the fluvial sequence in the uppermost part of the BOU profile is dated to 1.04-1.36 Ma (taking into account the uncertainties of samples C-E3824 and C-E3826) and contains crystalline and volcanic rocks, similar to the composition of the fan deposits and the upper gravel body of the GAR profile in the Triffa basin (Rixhon et al., 2017a). As the Kebdana mountains and the western part of the Beni Snassen massif are completely devoid of these rocks (Fig. 2a), we suggest bedload transport through the newly created Beni Snassen gorge and deposition further downstream in the Triffa plain. It would thus imply that the gorge formation related to the capture event is of Calabrian age and occurred between 1.04 and $1.36 \mathrm{Ma}$ at the latest. Provided that the crystalline and volcanic rock fraction originates from the uppermost Moulouya catchment (Aouli batholith), it would also imply that the Beni Snassen piracy event post-dates the capture episode of the upstream-located Ksabi-Missour basin (Fig. 1), which occurred at an unknown time period after the Early Pliocene (Pastor et al., 2015). A series of stream piracies that have occurred over the Quaternary are well-documented in the south-easternmost tip of the Iberian Peninsula as well (eastward of Almería, cf. Harvey et al., 2014). This region is characterised by a similar tectono-geodynamic setting (i.e., uplifted mountain blocks of the Bethic cordillera interspersed with intra-montane, Neogene/Quaternary basins) to that of our study area. Interestingly, some inter-basin connections may have been roughly contemporaneous with the one between the Guercif and Triffa basins: the establishment of the Río Almanzora transverse drainage through the Sierra Almagro, linking a formerly endorheic basin to the coastal Vera basin, is supposed to have occurred during the Calabrian-Middle-Pleistocene (Stokes and Mather, 2003; Harvey et al., 2014).

Finally, two features record post-capture river incision at the Beni Snassen gorge outlet: fan deposits are perched several tens of metres above the present-day valley bottom (Fig. 8c and d), and strath terraces carved into the Mesozoic bedrock, displaying abrasion flutes and poteholes (Fig. 8e), are observed several metres above the present channel. These post-capture incision episodes might be related to transient fluvial reactions in response to thrusting activity in the Triffa basin (Rixhon et al., 2017a).

\section{Summary and conclusion}

Draining the NW-SE convergence zone between the African and Eurasian plates, the lower Moulouya (NE Morocco) was affected by long-term tectonic activity. Pleistocene fluvial terraces on the lower $65 \mathrm{~km}$-long reach of the Moulouya River reflect crustal deformations due to a SW-NE striking fault zone. For the first time, the timing of these processes can be derived from the combination of different dating methods.

Due to the Calabrian to Middle Pleistocene age of the Moulouya terraces, establishing luminescence chronologies has been quite challenging, and only minimum ages could actually be produced in first instance. In contrast, ESR dating method provided a series numerical ages for the Calabrian fluvial deposits, which were found to be highly consistent with the independent palaeomagnetic results obtained from the same sections. This gives us a good confidence in the reliability and robustness of the first chronological framework that has been established for fluvial archives of the lower Moulouya, and demonstrates at the same time the high potential of the multiple centres (MC) approach in ESR dating. This framework will be completed in a near future by additional chronological constraints obtained from the application of new dating methods/approach on these deposits, like Terrestrial Cosmogenic Nuclides or Thermally Transferred (TT-)OSL dating.

These geochronological and geomorphological analyses contribute to further understand the environmental evolution of the lower Moulouya fluvial terraces in a tectonically active area related to the convergence between the African and Eurasian plates. This study reveals crustal deformations during Calabrian times associated with a main fault zone resulting in incision rates of $0.025 \pm 0.003 \mathrm{~mm} / \mathrm{a}$. The observations reported in this study validates the hypothesis of the $\mathrm{W}-\mathrm{E}$ striking main deformational front and N-S compressive shortening encompassed along faults between the Rif and Atlas Mountains (Fadil et al., 2006).

At the current state of research, it appears that the Triffa basins are characterised by an absence of Middle and Late Pleistocene fluvial formations. Consequently, the Calabrian fluvial record of the lower Moulouya points to an acyclic and discontinuous sedimentation pattern since $\sim 1.3 \mathrm{Ma}$ and seems to rule out climate as the main driver for long-term fluvial evolution. Observations in this study point to transient fluvial response to major tectonic activity that has occurred during the Calabrian along the Beni Snassen reach. The newly established chronostratigraphical framework implies that the gorge formation related to the capture event is of Calabrian age and occurred between 1.04 and $1.36 \mathrm{Ma}$ at the latest.

\section{Acknowledgements}

This project is affiliated to the CRC 806 "Our way to Europe", which is funded by the German Research Foundation [DFG; Grant-No.: SFB 806/2]. The support by the "Institut National des Sciences de l'Archéologie et du Patrimoine du Maroc" (INSAP) and by the "Commission for Archaeology of Non-European Cultures" (KAAK) of the German Archaeological Institute (DAI) is gratefully acknowledged, in particular by Abdeslam Mikdad and Josef Eiwanger, respectively. Meriam El Ouahabi and Martin Seeliger were of great help during field work. Aspects of the ESR dating study have been funded by the ARC Future Fellowship Grant FT150100215 awarded to Mathieu Duval. Verónica Guilarte (CENIEH) granted technical support in the ESR measurements. Anja Zander and Nicole Klasen 
(University of Cologne) helped with the luminescence and dosimetry measurements.

\section{Appendix A. Supplementary data}

Supplementary data related to this article can be found at https:// doi.org/10.1016/j.quascirev.2017.11.008.

\section{Unlisted references}

Rixhon 2016.

\section{References}

Ait Brahim, L., Chotin, P., Hinaj, S., Abdelouafi, A., El Adraoui, A., Nakcha, C., Dhont, D., Charroud, M., Sossey Alaoui, F., Amrhar, M., Bouaza, A., Tabyaoui, H., Chaouni, A., 2002. Paleostress evolution in the Moroccan African margin from triassic to present. Tectonophysics 357 (1-4), 187-205.

Arboleya, M.-L., Babault, J., Owen, L.A., Teixell, A., Finkel, R.C., 2008. Timing and nature of Quaternary fluvial incision in the Ouarzazate foreland basin, Morocco. J. Geol. Soc. 165, 1059-1073.

Auclair, M., Lamothe, M., Huot, S., 2003. Measurement of anomalous fading for feldspar IRSL using SAR. Radiat. Meas. 37, 487-492.

Balescu, S., Lamothe, M., 1993. Thermoluminescence dating of the holsteinian marine formation of Herzeele, northern France. J. Quat. Sci. 8 (2), 117-124.

Barathon, J.-J., El Abassi, H., Lechevalier, C., Malek, F., Jolly-Saad, M.-C., 2000. Mise au point sur les formations holocènes dans le Rif oriental (Maroc)/A chronology of Holocene deposits in the eastern Rif Mountains (Morocco). Géomorphologie: relief, processus, environnement. Octobre-décembre 6 (4), 221-238.

Barcos, L., Jabaloy, a., Azdimousa, a., Asebriy, L., Gómez-Ortiz, D., Rodríguez-Peces, M.J., Tejero, R., Pérez-Peña, J.V., 2014. Study of relief changes related to active doming in the eastern Moroccan Rif (Morocco) using geomorphological indices. J. Afr. Earth Sci. 100, 493-509.

Bartz, M., Klasen, N., Zander, A., Brill, D., Rixhon, G., Seeliger, M., Eiwanger, J., Weniger, G.-C., Mikdad, A., Brückner, H., 2015. Luminescence dating of ephemeral stream deposits around the Palaeolithic site of Ifri n'Ammar (Morocco) Quat. Geochronol. 30, 460-465.

Bartz, M., Rixhon, G., Kehl, M., El Ouhabi, M., Klasen, N., Brill, D., Weniger, G.-C., Mikdad, A., Brückner, H., 2017. Unravelling fluvial deposition and pedogenesis in ephemeral stream deposits in the vicinity of the prehistoric rock shelter of Ifri n'Ammar (NE Morocco) during the last $100 \mathrm{ka}$. Catena 152, 115-134.

Bell, W.T., 1980. Alpha dose attenuation in quartz grains for thermoluminescence dating. Anc. TL 12, 4-8.

Benito, G., Macklin, M.G., Zielhofer, C., Jones, A.F., Machado, M.J., 2015. Holocene flooding and climate change in the Mediterranean. Catena 130, 13-33.

Bouazza, A., Ait Brahim, 1., Dugué, O., Cattaneo, G., Laville, E., Delcaillau, B., Charroud, M., de Luca, P., 2009. Changements Sédimentaires dans les Bassins Nèogènes de Taourirt et Guercif (Maroc Oriental): recherche de L'épisode D'érosion Messinienne. Eur. J. Sci. Res. 28 (3), 317-327.

Boughriba, M., Melloul, A., Zarhloule, Y., Ouardi, A., 2006. Extension spatiale de la salinisation des ressources en eau et modèle conceptuel des sources salées dans la plaine des Triffa (Maroc nord-oriental). Comptes Rendus Geosci. 338, 768-774.

Bridgland, D., Westaway, R., 2008. Climatically controlled river terrace staircase: a worldwide Quaternary phenomenon. Geomorphology 98, 285-315.

Burbank, D.W., Anderson, R.S., 2012. Tectonic Geomorphology, second ed. Wiley-Blackwell, Oxford.

Buylaert, J.-P., Murray, A.S., Thomsen, K.J., Jain, M., 2009. Testing the potential of an elevated temperature IRSL signal from K-feldspar. Radiat. Meas. 44, 560-565.

Buylaert, J.-P., Jain, M., Murray, A.S., Thomsen, K.J., Thiel, C., Sohbati, R., 2012. A robust feldspar luminescence dating method for Middle and Late Pleistocene sediments. Boreas 41 (3), 435-451.

Cunha, P.P., Martins, A.A., Huot, S., Murray, A., Raposo, L., 2008. Dating the Tejo river lower terraces in the Ródão area (Portugal) to assess the role of tectonics and uplift. Geomorphology 102, 43-54

Cunha, P.P., Martins, A.A., Buylaert, J.-P., Murray, A.S., Raposo, L., Mozzi, P., Stokes, M., 2017. New data on the chronology of the Vale do Forno sedimentary sequence (Lower Tejo River terrace staircase) and its relevance as a fluvial archive of the Middle Pleistocene in western Iberia. Quat. Sci. Rev. 166, 204-226.

Demir, T., Seyrek, A., Westaway, R., Guillou, H., Scaillet, S., Beck, A., Bridgland, D.R., 2012. Late Cenozoic regional uplift and localised crustal deformation within the northern Arabian Platform in southeast Turkey: investigation of the Euphrates terrace staircase using multidisciplinary techniques. Geomorphology $165-166$, $7-24$.

Demoulin, A., Mather, A., Whittaker, A., 2017. Fluvial archives, a valuable record of vertical crustal deformation. Quat. Sci. Rev. 166, 10-37.
Duller, G.A.T., 1992. Luminescence Chronology of Raised Marine Terraces, South-west North Island, New Zealand. PhD dissertation University of Wales, Aberystwyth.

Durcan, J.A., King, G.E., Duller, G.A.T., 2015. DRAC: dose rate and age calculator for trapped charge dating. Quat. Geochronol. 28, 54-61.

Duval, M., 2012. Dose response curve of the ESR signal of the Aluminium centre in quartz grains extracted from sediment. Anc. TL 30 (2), 41-49.

Duval, M., Guilarte Moreno, V., 2012. Assessing the influence of the cavity temperature on the ESR signal of the Aluminium centre in quartz grains extracted from sediment. Anc. TL 30 (2), 51-56.

Duval, M., Guilarte, V., 2015. ESR dosimetry of optically bleached quartz grains extracted from Plio-Quaternary sediment: evaluating some key aspects of the ESR signals associated to the Ti-centres. Radiat. Meas. 78, 28-41.

Duval, M., Sancho, C., Calle, M., Guilarte, V., Penna-Monné, J.L., 2015. On the interest of using the multiple centre approach in ESR dating of optically bleached quartz grains: some examples from the Calabrian terraces of the Alcanadre River (Ebro basin, Spain). Quat. Geochronol. 29, 58-69.

Duval, M., Arnold, L.J., Guilarte, V., Demuro, M., Santonja, M., Pérez-Ganzález, A., 2017. Electron spin resonance dating of optically bleached quartz grains from the Middle Palaeolithic site of Cuesta de la Bajada (Spain) using the multiple centres approach. Quat. Geochronol. 37, 82-96.

El Amrani, M., Macaire, J.-J., Zarki, H., Bréhéret, J.-G., Fontugne, M., 2008. Contrasted morphosedimentary activity of the lower Kert River (northeastern Morocco) during the Late Pleistocene and the Holocene. Possible impact of bioclimatic variations and human action. C. R. Geoscience 340, 533-542.

Fadil, A., Vernant, P., McClusky, S., Reilinger, R., Gomez, F., Sari, D.Ben, Mourabit, T., Feigl, K., Barazangi, M., 2006. Active tectonics of the western Mediterranean: geodetic evidence for rollback of a delaminated subcontinental lithospheric slab beneath the Rif Mountains, Morocco. Geology 34, 529-532.

Gradstein, F.M., Ogg, J.G., Schmitz, M.D., Ogg, G.M. (Eds.), 2012. The Geologic Time Scale 2012, vol. 1, Elsevier, 144 p.

Guérin, G., Mercier, N., Adamiec, G., 2011. Dose-rate conversion factors: update. Anc. TL 29, 5-8.

Guérin, G., Mercier, N., Nathan, R., Adamiec, G., Lefrais, Y., 2012. On the use of the infinite matrix assumption and associated concepts: a critical review. Radiat. Meas. 47, 778-785.

Guralnik, B., Jain, M., Herman, F., Ankjærgaard, C., Murray, A.S., Valla, P.G., Preusser, F., King, G.E., Chen, R., Lowick, S.E., Kook, M., Rhodes, E.J., 2015. OSL-thermochronometry of feldspar from the KTB Borehole. Germany. Earth Planet. Sci. Lett. 423, 232-243.

Harvey, A.M., Elizabeth Whitfield, E., Stokes, M., Mather, A., 2014. The late Neogene to quaternary drainage evolution of the uplifted Neogene sedimentary basins of Almeria. In: Chain, Betic, Gutiérrez, F., Gutiérrez, M. (Eds.), Landscapes and Landforms of Spain. World Geomorphological Landscapes, Springer, Dordrecht, pp. 37-61.

Huntley, D.J., 2006. An explanation of the power-law decay of luminescence. J. Phys. Condens. Matter 18, 1359-1365.

Huntley, D.J., Baril, M.R., 1997. The K content of the K-feldspars being measured in optical dating or in thermoluminescence dating. Anc. TL 15 (1), 11-13.

Huntley, D.J., Lamothe, M., 2001. Ubiquity of anomalous fading in K-feldspars and the measurement and correction for it in optical dating. Can. J. Earth Sci. 38, 1093-1106.

Huntley, D.J., Lian, O.B., 2006. Some observations on tunnelling of trapped electrons in feldspars and their implications for optical dating. Quat. Sci. Rev. 25 (19-20), 2503-2512.

Jacobson, R.B., Elston, D.P., Heaton, J.W., 1988. Stratigraphy and magnetic polarity of the high terrace remnants in the upper Ohio and Monongahela rivers in West Virginia, Pennsylvania and Ohio. Quat. Reasearch 29, 216-232.

Kars, R.H., Wallinga, J., Cohen, K.M., 2008. A new approach towards anomalous fading correction for feldspar IRSL dating - tests on samples in field saturation. Radiat. Meas. 43, 786-790.

Kars, R.H., Wallinga, J., 2009. IRSL dating of K-feldspars: modelling natural dose response curves to deal with anomalous fading and trap competition. Radiat. Meas. $44(5-6)$, 594-599.

Khattach, D., Keating, P., Mili, E.M., Chennouf, T., Andrieux, P., Milhi, A., 2004. Apport de la gravimétrie à l'étude de la structure du bassin des Triffa (Maroc nord-oriental): implications hydrogéologiques. Comptes Rendus Geosci. 336, 1427-1432.

King, G.E., Herman, F., Guralnik, B., 2016. Northward migration of the eastern Himalayan syntaxis revealed by OSL thermochronometry. Science 353 (6301), 800-804.

Le Roux, J., Harmand, D., 1998. Contrôle morphostructural de l'histoire d'un réseau hydrographique: le site de la capture de la Moselle. Geodin. acta 11 (4), 149-162.

Li, J.-J., Fang, X.-M., Van der Voo, R., Zhu, J.-J., Niocaill, C.M., Ono, Y., Pan, B.-T., Zhong, W., Wang, J.-L., Sasaki, T., Zhang, Y.-T., Cao, J.-X., Kang, S.-C., Wang, J.-M., 1997. Magnetostratigraphic dating of river terraces: rapid and intermittent incision by the Yellow River of the northeastern margin of the Tibetan Plateau during the Quaternary. J. Geophys. Res. 102 (B5), 10121-10132.

Li, B., Li, S.-H., 2008. Investigations of the dose-dependent anomalous fading rate of feldspar from sediments. J. Phys. D Appl. Phys. 41 (225502), 15 p. 
Li, Y., Tsukamoto, S., Frechen, M., Gabriel, G., 2017. Timing of fluvial sedimentation in the upper Rhine Graben since the middle pleistocene: constraints from quartz and feldspar luminescence dating. Boreas https://doi.org/10.1111/bor.12266, ISSN 0300-9483.

Lin, M., Yin, G., Ding, Y., Cui, Y., Chen, K., Wu, C., Xu, L., 2006. Reliability study on ESR dating of the aluminium center in quartz. Radiat. Meas. 41, 1045-1049.

Linstädter, J., Aschrafi, M., Ibouhouten, H., Zielhofer, C., Bussmann, J., Deckers, K., Müller-Sigmund, H., Hutterer, R., 2012. Flussarchäologie der Moulouya-Hochflutebene, NO-Marokko. Madr. Mittl. 53, 1-84.

Martins, A.A., Cunha, P.P., Buylaert, J.-P., Huot, S., Murray, A.S., Dinis, P., Stokes, M., 2010. K-feldspar IRSL dating of a Pleistocene river terrace staircase sequence of the Lower Tejo River (Portugal, western Iberia). Quat. Geochronol. 5, 176-180.

Macklin, M.G., Fuller, I.C., Lewin, J., Maas, G.S., Passmore, D.G., Rose, J., Woodward, J.C., Black, S., Hamlin, R.H.B., Rowan, J.S., 2002. Correlation of fluvial sequences in the Mediterranean basin over the last $200 \mathrm{ka}$ and their relationship to climate change. Quat. Sci. Rev. 21 (14-15), 1633-1641.

Meghraoui, M., Morel, J.-L., Andrieux, J., Dahmani, M., 1996. Tectonique plio-quaternaire de la chaine tello-riffaine et de la mer d'alboran. Une zone compexe de convergence continent-continent. Bull. Société Géologique Fr. 167, 141-157.

Meghraoui, M., Pondrelli, S., 2012. Active faulting and transpression tectonics along the plate boundary in North Africa. Ann. Geophys. 55 (5), 955-967.

Pastor, A., Babault, J., Owen, L.A., Teixell, A., Arboleya, M.-L., 2015. Extracting dynamic topography from river profiles and cosmogenic nuclide geochronology in the Middle Atlas and the high plateaus of Morocco. Tectonophysics 663, 95-109.

Pérez-Peña, J.V., Azañón, J.M., Azor, A., Delgado, J., González-Lodeiro, F., 2009. Spatial analysis of stream power using GIS : SLk anomaly maps. Earth Surf. Process. Landforms 34 (1), 16-25.

Pissart, A., Boumeaza, T., 2010. Âge et origine de la terrasse limoneuse de la basse Moulouya (Maroc Nord-Oriental). Bull. Société Géogr. Liège 54, 85-96.

Poujol, A., Ritz, J.-F., Tahayt, A., Vernant, P., Condomines, M., Blard, P.-H., Billant, J., Vacher, L., Tibari, B., Hni, L., Idrissi, A.K., 2014. Active tectonics of the Northern Rif (Morocco) from geomorphic and geochronological data. J. Geodyn. $77,70-88$.

Prescott, J.R., Hutton, J.T., 1994. Cosmic ray contributions to dose rates for luminescence and ESR dating: large depths and long-term time variations. Radiat. Meas. 23, 497-500.

Ramón, M.J., Pueyo, E.L., 2012. Automatic calculation of demagnetization intervals; a new approach based on the virtual directions method and comparison with the linearity spectrum análisis. Geotemas 13, 1080-1083.

Rixhon, G., Bartz, M., El Ouahabi, M., Szemkus, N., Brückner, H., 2017a. Contrasting terrace systems of the lower Moulouya river as indicator of crustal deformation in NE Morocco. J. Afr. Earth Sci. 126, 45-57.

Rixhon, G., Briant, R.M., Cordier, S., Duval, M., Jones, A., Scholz, D., 2017b. Revealing the pace of river landscape evolution during the Quaternary: recent developments in numerical dating methods. Quat. Sci. Rev. 166, 91-113.

Ruellan, A., 1971. Contribution à la connaissance des sols des régions méditerranénnes: les sols à profil calcaire différencié des plaines de la basse Moulouya (Maroc oriental). Mémoire Off. Rech. Sci. Tech. d'Outre-Mer302 pp.

Saadi, M., 1982. Carte structurale du Maroc. Notes et mémoires du Service Géologique du Maroc, $\mathrm{n}^{\circ}$ 278. Ministère de l'Energie et des Mines, Royaume du Maroc.

Sancho, C., Calle, M., Peña-Monné, J.L., Duval, M., Oliva-Urcia, B., Pueyo, E.L., Benito, G., Moreno, A., 2016. Dating the earliest Pleistocene alluvial terrace of the Alcanadre river (Ebro basin, NE Spain): insights into the landscape evolution and involved processes. Quat. Int. 407, 86-95.

Sani, F., Zizi, M., Bally, A.W., 2000. The Neogene-Quaternary evolution of the Guercif Basin (Morocco) reconstructed from seismic line interpretation. Mar. Petroleum Geol. 17 (3), 343-357.

Santisteban, J.I., Schulte, L., 2007. Fluvial networks of the Iberian Peninsula: a chronological framework. Quat. Sci. Rev. 26, 2738-2757.

Sardinha, J., Carneiro, J.F., Zarhloule, Y., Barkaoui, A., Correia, A., Boughriba, M., Rimi, A., El Houadi, B., 2012. Structural and hydro geological features of a lias carbonate aquifer in the Triffa Plain, NE Morocco. J. Afr. Earth Sci. 73-74, 24-32.

Schulte, L., 2002. Climatic and human influence on river systems and glacier fluctuations in southeast Spain since the last glacial maximum. Quat. Int. 93-94, 85-100.
Schulte, L., Julià, R., Burjachs, F., Hilgers, A., 2008. Middle Pleistocene to Holocene geochronology of the river Aguas terrace sequence (Iberian Peninsula): fluvial response to Mediterranean environmental change. Geomorphology 98, 13-33.

Singer, B.S., 2014. A Quaternary geomagnetic instability time scale. Quat. Geochronol. 21, 29-52.

Soria-Jáuregui, , González-Amuchástegui, M.J., Mauz, B., Lang, A., 2016. Dynamics of Mediterranean late quaternary fluvial activity: an example from the river Ebro (north Iberian Peninsula). Geomorphology 268, 110-122.

Stokes, M., Mather, A.E., 2003. Tectonic origin and evolution of a transverse drainage: the Río Almanzora, betic cordillera; southeast Spain. Geomorphology 50 (1-3), 59-81.

Stokes, M., Mather, A.E., Belfoul, M., Faik, F., Bouzid, S., Geach, M.R., Cunha, P.P., Boulton, S.J., Thiel, C., 2017. Controls on dryland mountain landscape development along the NW Saharan desert margin: insights from Quaternary river terrace sequences (Dadès River, south-central High Atlas, Morocco). Quat. Sci. Rev. 166, 363-379.

Tauxe, L., 1998. Paleomagnetic Principles and Practice. Springer, New York, 299 pp.

Thiel, C., Buylaert, J.P., Murray, A.S., Tsukamoto, S., 2011a. On the applicability of post-IR IRSL dating to Japanese loess. Geochronometria 38, 369-378.

Thiel, C., Buylaert, J.-P., Murray, A., Terhorst, B., Hofer, I., Tsukamoto, S., Frechen, M., 2011 b. Luminescence dating of the Stratzing loess profile (Austria) - testing the potential of an elevated temperature post-IR IRSL protocol. Quat. Int. 234, 23-31.

Thomsen, K.J., Murray, A.S., Jain, M., Bøtter-Jensen, L., 2008. Laboratory fading rates of various luminescence signals from feldspar-rich sediment extracts. Radiat. Meas. 43, 1474-1486.

Toyoda, S., Voinchet, P., Falguères, C., Dolo, J.M., Laurent, M., 2000. Bleaching of ESR signals by the sunlight: a laboratory experiment for establishing the ESR dating of sediments. Appl. Radiations Isotopes 52, 1357-1362.

Toyoda, S., Falguères, C., 2003. The method to represent the ESR signal intensity of the aluminium hole centre in quartz for the purpose of dating. Adv. ESR Appl. 20, $7-10$.

Vandenberghe, D., De Corte, F., Buylaert, J.-P., Kučera, J., Van den Haute, P., 2008. On the internal radioactivity in quartz. Radiat. Meas. 43, 771-775.

Voinchet, P., Falguères, C., Laurent, M., Toyoda, S., Bahain, J.J., Dolo, J.M., 2003. Artificial optical bleaching of the Aluminium center in quartz: implications to ESR dating of sediments. Quat. Sci. Rev. 22, 1335-1338.

Voinchet, P., Despirée, J., Tissoux, H., Falguères, C., Bahain, J.-J., Gageonnet, R., Dépont, J., Dolo, J.-M., 2010. ESR chronology of alluvial deposits and first human settlements of the Middle Loire Basin (Region Centre, France). Quat. Geochronol. 5, 381-384.

Wintle, A., 1973. Anomalous fading of thermoluminescence in mineral samples. Nature $245,143-144$

Wintle, A.G., Murray, A., 2006. A review of quartz optically stimulated luminescence characteristics and their relevance in single-aliquot regeneration dating protocols. Radiat. Meas. 41, 369-391.

Woda, C., Wagner, G.A., 2007. Non-monotonic dose dependence of the Ge- and Ti-centres in quartz. Radiat. Meas. 42, 1441-1452.

Wolf, D., Seim, A., Faust, D., 2014. Fluvial system response to external forcing and human impact - late Pleistocene and Holocene fluvial dynamics of the lower Guadalete River in western Andalucía (Spain). Boreas 43, 422-429.

Yokoyama, Y., Falguères, C., Quaegebeur, J.P., 1985. ESR dating of quartz from Quaternary sediments: first attempt. Nucl. Tracks 10 (4-6), 921-928.

Zielhofer, C., Faust, D., Linstädter, J., 2008. Late Pleistocene and Holocene alluvial archives in the southwestern Mediterranean: changes in fluvial dynamics and past human response. Quat. Int. 181, 39-54.

Zielhofer, C., Bussmann, J., Ibouhouten, H., Fenech, K., 2010. Flood frequencies reveal Holocene rapid climate changes (Lower Moulouya River, northeastern Morocco). J. Quat. Sci. 25 (5), 700-714.

Zijderveld, J.D.A., 1967. A.C. Demagnetization of rocks: analysis of results. In: Collinson, D.W., Creer, K.M., Runcorn, S.K. (Eds.), Methods in Palaeomagnetism. Elsevier, Amsterdam, New York, pp. 254-286. 